\title{
NAZIS Y CHARLATANES EN ARGENTINA. ACERCA DE MITOS E HISTORIA TERGIVERSADA
}

IGNACIO KLICH

(Universidad de Buenos Aires)

CRISTIAN BUCHRUCKER

(CONICET, Universidad Nacional de Cuyo)

Dos décadas han trascurrido desde el inicio de un acceso más fluido a la documentación sobre los nazis acumulada en distintos repositorios argentinos. Si bien tardía, esta medida propicia, primero efectivizada no más que apenas, luego con mayor amplitud, comenzó a verse implementada a partir de 1992. Desde entonces, el grueso de la producción sobre esta vasta temática -básicamente la del periodismo investigativo local- ha dado pocas señales de haberse servido del consecuente acrecimiento de la materia prima disponible.

La calidad de gran parte de esa producción periodística revela, en todo caso, que ella no ha abrevado demasiado en tan rica, aún si incompleta, fuente. En rigor, tales escritos se produjeron mayormente con prescindencia de casi todo el material de archivos argentinos y extranjeros, como si estos papeles no existiesen o el acceso a ellos estuviese enteramente vedado. En el mejor de los casos, están quienes han re- currido ocasional y selectivamente a una cantidad insignificante de documentos, priorizando hallazgos personales de difícil consulta por terceros, salvo para quienes se den por satisfechos con las copias facsimilares ocasionalmente reproducidas por tales periodistas, y citando a los demás de manera indirecta y descontextualizada. Un caso más extremo de la misma falta es el de quienes escriben con casi la más absoluta prescindencia de la documentación e historiografía, como si se pudiese lograr un texto de historia seria a puro artificio, con asertos cuya validez está más allá del aporte de evidencia firme en su apoyo.

Como posible justificación de tan limitado aprovechamiento de los registros disponibles, no escasean las alusiones a «miles y miles de documentos» más, «guardados en inasibles archivos que nadie tiene interés en mostrar y que son difíciles de hallar ${ }^{1}$. Es ésta una suerte de minimización de lo ya desclasificado por doquier. Y viene

${ }^{1}$ Carlos de Nápoli, La fórmula de la juventud eterna y otros experimentos nazis, Buenos Aires, Norma, 2009, p. 71. 
realzada por quejas difícilmente inesperadas por actitudes enojosas de las autoridades de algunos repositorios locales. Inversamente proporcionales a los detalles suministrados por los quejosos respecto de sus hallazgos personales, tales reclamos ni son válidos para todos los repositorios argentinos, ni tienen en cuenta incordios que, demás está decir, no deberían existir en ningún lugar, a los que también han estado expuestos quienes han recurrido a archivos extranjeros ${ }^{2}$. Con respeto, todo ello conforma desdichadamente una excusa, tristemente empleada por quienes intentan hermosear una variedad de déficits.

Junto a una actitud selectiva frente a las fuentes -cualquiera la categoría de lo desechado-, la mayor de tales minusvalías es la ausencia de un examen riguroso de la documentación original ya accesible, consulta implícitamente desaconsejada al magnificarse lo que resta a ser desclasificado. Si es tanto lo que no puede consultarse aun, ¿qué sentido tiene ver lo disponible? $\mathrm{Y}$ en un medio en el que la adicción a las teorías conspirativas es moneda corriente - proclividad alimentada por los decenios de cultura del secreto-, ¿`cómo creer que lo ingresado al dominio público no apunta a despistar a ingenuos y curiosos?
La respuesta a esos interrogantes requiere tener presente que es equivocado suponer que Argentina y/u otros ya dieron a conocer íntegramente todo lo que sus respectivos repositorios atesoraban a este respecto, y más concretamente que la antes mencionada cultura del secreto ha quedado completamente superada por las alentadoras mutaciones habidas. Además, resulta difícilmente realista proponerse dimensionar con seriedad, siquiera aproximadamente, la enormidad de los registros inhallables en instalaciones supuestamente secretas, sean éstos millares o cifras más modestas. Corresponde, por tanto, trabajar con todo lo disponible hoy, conscientes de que la historia se construye ladrillo a ladrillo, careciendo la edificación resultante, más aun aquélla referida a la historia reciente, del correspondiente certificado de terminación de obra, en este caso de veredictos finales. A tono con su periódico reaprendizaje, tal como lo abogaba el historiador británico Tony Judt, es entonces imperativo revisar periódicamente lo conocido a la luz de cambios significativos, por caso nuevas acrecencias de fuentes, que incuestionablemente tienden a gestar discusiones inéditas e interpretaciones diferentes.

\footnotetext{
2 Sobre dificultades encontradas, por caso, en el Palacio Santa Cruz, archivo de la cancillería hispana, ver recensión de Ignacio Klich sobre el libro de José María Irujo, La lista negra. Los espías nazis protegidos por Franco y la Iglesia, en: Estudios Sociales, año XIV, № 27, Santa Fe, Universidad Nacional del Litoral, 2004, p. 205.
} 
En cambio, lo que no debe hacerse es tergiversar lo que está bien documentado, o intentar maquillar la consulta evitada de las fuentes existentes con referencias al trabajo de quienes supuestamente habrían visto los registros relevantes. Es éste un camuflaje del irrealizado relevamiento de los papeles disponibles y, con él, un intento de distanciamiento del envejecimiento y obsolescencia de su contenido, cuando no de la información imprecisa que, ab initio, los documentos sobre cualquier tema asimismo puede contener.

A modo de muestra sobre aproximaciones indirectas a las fuentes e insuficiente evaluación de las mismas, así como de selectividad en materia de documentación e historiografía relevada, sirva de botón un trabajo de Nahuel Coca sobre los submarinos del Tercer Reich en Argentina. Éste representa un resumen pulido y mejor acabado de lo sostenido por algunos autores sobre tales sumergibles. Desde Silvano Santander hasta Abel Basti, autor inicialmente de una guía turística sobre sitios reales o ficticios de los nazis aquí ${ }^{3}$, e incluyendo a los periodistas Jorge Camarasa, Carlos de Nápoli, ellos suponen que la costa argentina fue escenario del arribo de más submarinos que el co- nocido par que se rindió en 1945 en Mar del Plata -el U-530 y el U-977-, albergando sus honduras los restos de sumergibles hundidos antes o después del fin de la conflagración mundial.

El interés provocado por tales naves es fácilmente explicable. Entre sus distintas raíces, es un nutriente de la noción de que un Adolf Hitler prófugo fue uno de sus pasajeros, venido a instalarse aquí. Varios son los autores que se han quedado fijados a esta hipótesis desgastada, refutada por la historiografía más seria. Ésta contradice la alegada sobrevida del entonces Fuehrer, por ejemplo en una estancia de las inmediaciones de Bariloche. Con amabilidad, esa versión alentada por Basti, entre otros, es descollante en materia de tergiversación de la documentación e historiografía cuando sostiene imaginariamente, por caso, que no existen «dictámenes soviéticos» sobre el suicidio de Hitler, presentando además al jurista estadounidense Michael Musmanno como habiendo opinado en 1946 que el ex Fuehrer "había escapado» ${ }^{4}$. Hasta ahora nunca refutado, un documento de inteligencia soviética de 1945 concluyó que el cadáver de Hitler había sido positivamente hallado, y el juez Musmanno, tras acumular veinte tomos

\footnotetext{
${ }^{3}$ Abel Basti, Bariloche nazi. Sitios históricos relacionados al nacionalsocialismo: Incluye los lugares donde vivieron Adolf Hitler y Eva Braun cuando escaparon de Berlín, Edición del autor, 2004.

${ }^{4}$ Abel Basti, El exilio de Hitler. Las pruebas de la fuga del Führer a la Argentina, Buenos Aires, Sudamericana, 2010, pp. 136, 304.
} 
de documentos, remató años después que «no existe la menor evidencia para dudar de la muerte de Hitler» en su refugio berlinés 5 . Es ésta una constatación inalterada por los historiadores que se ocuparon del tema luego. Corresponde, pues, diferenciar a Hitler de un elenco de criminales de guerra de distintas nacionalidades -no menos de 180, según la Comisión para el Esclarecimiento de las Actividades del Nazismo en la Argentina (CEANA) ${ }^{6}$, que, cualquiera su nacionalidad, sí afluyeron al país, siguiendo una variedad de rutas, empleando distintos medios de transporte, contando con un conjunto variopinto de apoyos extranjeros y locales, y afincándose en distintos lugares, Bariloche incluido. $\mathrm{Y}$ a contrapelo de quienes transitaron en años recientes de la magnificación cuantitativa a la cualitativa de la importancia argentina como indudable país receptor de nazis, o bien siguen aferrados a la amplificación cuanticualitativa de Argentina como «la Meca de los nazis», el historia-

\begin{abstract}
${ }^{5}$ Para la primera versión castellana de ese documento soviético, ver «Apéndice documental», en: Ignacio Klich y Cristian Buchrucker (comps.), Argentina y la Europa del nazismo. Sus secuelas, Buenos Aires, Siglo XXI, 2009, pp. 359-360. Para una discusión del papel del juez Musmanno, y de los documentos soviéticos sobre el suicidio de Hitler, ver asimismo el trabajo de Ignacio Klich y Cristian Buchrucker, «El final del Tercer Reich y la «conexión argentina) en la literatura revisionista», en el volumen antes mencionado, pp. 255-256, 277-284.

${ }^{6}$ Creada en 1997 por el gobierno de Carlos Menem, y apoyada por éste y sus sucesores hasta 2005, la CEANA fue responsable ante un Panel Internacional y Comité Asesor conformados por personalidades e instituciones con interés en la temática, mayoritariamente ajenos a los partidos gobernantes durante ese período. En otras palabras, no fue una Comisión Nacional, a responderle al jefe de Estado o su gobierno. Aun así, Camarasa cree poder ligar la creación de la CEANA a un texto del autor estadounidense Gerald Posner, que el New York Times (07/12/1992) publicitó cinco años antes, y le adscribe a Menem la intención de querer darle «un 'punto final'» rápidamente a este tema. De haber sido esa la intención oficial, podría pensarse que ello pone en duda los hallazgos de la Comisión. No sorprende que Camarasa omita fechas y demás detalles relevantes sobre la CEANA, entre otras razones, por la imposibilidad de evidenciar que el gobierno de Fernando de la Rúa hubiese compartido ese supuesto «punto final» precoz como objetivo, en caso de haber sido ésta la meta de Menem. Por añadidura, el retrato de Camarasa es también imposible de conciliar con los ocho años de vida de la Comisión, así como con las personalidades e instituciones judías de su Panel Internacional y Comité Asesor. De paso, Camarasa sostiene que el objetivo que le adscribe a Menem lo recogió del historiador Ronald Newton, a la sazón uno de los vicepresidentes del Comité Académico de la CEANA, en una entrevista publicada por el matutino La Nación en un suplemento asombrosamente «sin fecha». Reveladora, entre otras cosas, de la propensión de Camarasa a acomodar los hechos a ideas preconcebidas, la falta de fecha de ese suplemento de La Nación dista de ser real: los interesados en esa entrevista pueden consultarla en su sección Enfoques del 14/12/97. Pero sin ese ocultamiento icómo atar el génesis de la CEANA al escrito de Posner de un quinquenio antes? Y ¿cómo evitar que el lector juzgue por sí solo lo dicho por Newton? Jorge Camarasa, Puerto seguro. Desembarcos clandestinos en la Patagonia, Buenos Aires, Norma, 2006, p. 114, n. 52.
\end{abstract}


dor alemán Ulrich Herbert publicitó una conclusión compartida por otros estudiosos germanos: «casi todos los nazis de alta graduación que sobrevivieron la guerra y la posguerra, al igual que aquéllos en la Gestapo y las SS, (...) habían estado viviendo pacíficamente por décadas en el seno de nuestra sociedad $»$. Ergo, no habrían podido estar simultáneamente aquí, realidad que no habilita la pérdida de vista de los criminales de guerra nazis llegados al país. Volviendo a los sumergibles, su búsqueda está ligada asimismo a serias expectativas materiales: desde primas por el rescate de expolio nazi a ser hallado, hasta la más factible capitalización del interés de parte del público en la historia popular, sus filmes et al, que, con el apoyo de instituciones acaso naturalmente interesadas en los usos políticos de la historia, le han permitido a algunos desviar la atención del público a la vía muerta de especulaciones huérfanas de asidero en la realidad.

Aferrarse a esas especulaciones, práctica relativamente habitual entre los cultores de las teorías conspirativas, depende críticamente de desestimar investigaciones históricas realizadas llenando los espacios en blanco dejados por la documentación argentina con los valiosos registros de una variedad de archivos de otros países, ora para entrecruzarla con éstos, ora para que los segundos, con sus limitaciones, permitan intentar remediar la ausencia de la primera. Dada esa ausencia, no es secreto que las más tempranas investigaciones académicas locales sobre la actuación argentina durante la Segunda Guerra Mundial y temprana posguerra se basaron esencialmente en registros británicos y/o estadounidenses. Lejos de ser ésta una exclusividad argentina, los autores israelíes de trabajos sobre la búsqueda de Adolf Eichmann y otros criminales del nazismo, por caso, debieron recurrir a más repositorios que los de su país al no haber hallado en éstos gran cosa, pese al interés en el tema de Israel y a contar éste con una ley de libre acceso a la información. En línea con esa realidad, un editorialista de un periódico hebreo ajeno al sensacionalismo llamó a evitar seguir postergando la desclasificación de la documentación acopiada por el servicio de inteligencia israelí sobre tales criminales ${ }^{8}$. Con el mismo fin, el ya aludido entrelazamiento de la documentación también corresponde hacerlo con las fuentes orales y de prensa, la historiografía, e inesperadamente por lo novedoso, con la arqueología subacuática en el tema de los submarinos también. Tal lo efectuado, por caso, por el historiador estadounidense Ronald Newton por un lado, y por el otro por dos especialis-

\footnotetext{
7 Tageszeitung, 11/04/2011.

${ }^{8}$ Haaretz, 01/05/2011.
} 
tas argentinos en esa arqueología, Mónica Valentini y Javier García Cano, equivalentes hoy de los zahoríes de antaño9. Pese a los denodados esfuerzos desplegados, sus respectivas búsquedas resultaron vanas: no lograron dar con ningún sumergible.

A la luz de esos resultados, puede argüirse que Coca quizás exhibe una certidumbre desmedida respecto de la existencia de más submarinos que el par que se rindió. Por añadidura, esa desmesura viene apuntalada por fuentes que curiosamente le pintan a Coca un notable talón de Aquiles: el desconocimiento de idiomas distintos del propio. De confirmarse tal impericia lingüística, definitivamente documentada en los trabajos de otros autores que Coca cita, ella deja claramente expuesta la discapacidad de todos ellos para sacarle provecho a las fuentes documentales en lenguas europeas ajenas al castellano, ya no hablemos de exprimirle información a una frondosa historiografía, principalmente en inglés y/o alemán. Adicionalmente, también ayuda a explicar la abundancia de grafías defectuosas, un alifafe tan presente en la transcripción de nombres alemanes y anglosajones por varios de los periodistas citados por Coca. Con respeto, la minusvalía lingüística se ve potenciada por el predominio de autores raramente confiables entre los mencionados en el aparato erudito de esta pieza, desde el ex legislador Santander, políticamente bienintencionado pero exclusivo productor de literatura de combate largamente caducada, hasta sus legatarios sensacionalistas del periodismo local, bastante creídos que la corrección de su sesgo político actual y, más importante aún, el auspicio que disfrutan de instituciones ligadas al mantenimiento en el candelero de versiones reñidas con la mejor historiografía sobre el tema-por caso, la sobrevida del ex delfín de Hitler, Martin Bormann ${ }^{10}-$, les confiere la insólita potestad de no tener que probar nada. Con mayor especificidad, una fuente crucial de uno de los avizoramientos «más relevantes» de submarinos sería, de acuerdo con Coca, un testigo directo de por lo menos un avistamiento: el policía Ricardo Montero. En julio de 1945, éste informó al comisario de Necochea haber observado

\footnotetext{
9 Ronald C. Newton, «Las actividades clandestinas de la marina alemana en aguas argentinas entre 1930 y 1945, con especial referencia a la rendición de dos submarinos germanos en Mar del Plata en 1945», en: Ignacio Klich y Cristian Buchrucker, pp. 65-100; Mónica Valentini y Javier García Cano, «Arqueología e historia. La búsqueda de los submarinos alemanes en aguas argentinas», en: Ignacio Klich y Cristian Buchrucker, Argentina y la Europa del nazismo, op. cit., pp. 101-19.

${ }^{10}$ Ignacio Klich y Cristian Buchrucker, «El fin del Tercer Reich y la sconexión argentina) en la bibliografía revisionista», en Ignacio Klich y Cristian Buchrucker, Argentina y la Europa del nazismo, op. cit., pp. 270-276.
} 
«un bulto negro que le pareció» era un submarino, dejando constancia, sin embargo, de no estar muy seguro al respecto ${ }^{11}$. Al igual que un coetáneo avizoramiento en la costa bonaerense del U-124 -imaginario, en la medida en que ese sumergible había sido hundido dos años antes-, la inseguridad de Montero no debe sorprender dada la multiplicidad de presuntos avistajes de submarinos alemanes en éste $\mathrm{u}$ otros continentes durante la conflagración mundial, e inmediatamente después.

$\mathrm{Al}$ no ser Montero tan longevo, conviene tener presente que la verdadera fuente de Coca sobre lo que el policía creyó haber visto no es él, sino su hijo. Éste, sin embargo, no estuvo presente cuando su padre divisó el reportado bulto. Coca busca remontar ese inconveniente con el hecho, entre otros, de que tal descendiente del policía estaba dotado de muy buena memoria, siendo él, entonces, el informante de un sinfín de detalles, algunos escuchados de su padre y otros, al parecer, también atestiguados por él.

Lo detallado tiene que ver con la ulterior detención de un artesano que "confesó» haber entrado en contacto con un submarino deseoso de atracar «en algún lugar seguro de la costa (...) para desembarcar», y con el posterior rastrillaje policial de la playa, procedimiento en el que, acompañando a su padre, se halló una variedad de huellas: rastros que iban y venían de «un importante establecimiento agrícola» de propietarios alemanes, además de trazas «de cajones que habían sido arrastrados hasta unos camiones». En el racconto de Montero (h) el intento del comisario y su padre de ingresar a esa finca fue repelido por «cuatro alemanes con ametralladoras en mano», y más tarde abortado por orden de la superioridad ${ }^{12}$. Infortunadamente, esto tampoco proviene de una entrevista con el hijo del testigo real -de ser ello posible, éste estaría hoy orillando los 80 años-, sino más indirectamente de una carta suya que no estaba dirigida a Coca. Según Camarasa, tal misiva lo tenía a él mismo por destinatario: infelizmente para los ajenos al tema, este autor es responsable de un rosario de ficciones no corregidas en varios de sus libros, por caso su tratamiento de los documentos que Juan Perón puso a disposición de ex cuadros del Tercer Reich y otros. Sea que procurase protegerse de ese déficit documentado u otras razones, Coca se aparta de Camarasa al omitir que -según este periodista- Montero (p) habría sido vapuleado por sus superiores hasta que se desdijo. Presionado o no, éste concluyó

${ }^{11}$ Nahuel Coca, «Submarinos nazis en la Argentina», en: Todo es Historia, año XLIII, № 516, Buenos Aires, julio, 2010, pp. 14-15.

12 Coca, pp. 14-15. 
que el bulto que inicialmente había creído un sumergible pudo haber sido otra cosa, tal como surgía de su incertidumbre original, y también de la carta de Montero (h), cuando afirmaba que en una nueva detección posible de la misma nave, horas después de la de su padre, "no se sabía si era un submarino o un barco» ${ }^{13}$.

A renglón seguido, Coca recurre a Santander, creyendo hallar en un texto de denuncia suyo, Técnica de una traición. Juan D. Perón y Eva Duarte, agentes del nazismo en la Argentina, refuerzos a lo deletreado en la carta que Camarasa dice haber recibido de Montero (h): se trata del testimonio en la legislatura argentina de marinos alemanes antes afectados al acorazado de bolsillo Graf Spee. En palabras de Coca, sus "supuestas declaraciones» están referidas a la llegada de dos sumergibles adicionales, tratándose especialmente en ellas la descarga en fecha semejante a la de las pesquisas de Montero (p) de «una valiosa carga que venía de Alemania», además del desembarco de 80 personas, algunas «muy importantes», en una estancia de los mismos propietarios alemanes. Verificados por otro autor con uno de esos marineros, Coca se abstiene, empero, de abundar sobre los resultados de ese juicioso ejercicio.
Tal proceder parece inconsistente con una prudente dosis de desconfianza suya, ésta plasmada en su visión de lo reportado por esos marinos como «supuestas declaraciones». La actitud de Coca puede sorprender asimismo por haber aclarado él suplementariamente algo que distintos predecesores suyos pasaron por alto: nadie "pudo dar con los registros taquigráficos de estas declaraciones ante el Congreso» ${ }^{14}$. Como si una carencia tal sólo fuese una nimiedad, Camarasa es de los que se han permitido ignorarla, dejándola también de tener presente en su labor, por caso, como guionista de Oro nazi en Argentina, filme que a criterio del académico estadounidense Joseph Page alcanzó el dudoso logro - ¡vaya espaldarazo!- de familiarizar a sus espectadores con «reconstrucciones sensacionalistas de hechos que probadamente nunca ocurrieron $»^{15}$. Al igual que las fantasías aparecidas en los libros de Camarasa, tal observación de Page afecta la credibilidad de este híbrido entre documental y ficcionalización de lo que el primero quiso recalcar, excepto para quienes no conocen del tema, o ven tales ficciones a la luz de teorías propias, alejadas de la realidad.

En suma, la observación inicial del policía ha sido suplantada por la narración de

\footnotetext{
${ }^{13}$ Camarasa, Puerto seguro, p. 172.

${ }^{14}$ Coca, p. 19, n. 24.

${ }_{15}$ Joseph A. Page, «Prólogo», en: Ignacio Klich y Cristian Buchrucker, Argentina y la Europa del nazismo, p. 8.
} 
quien estuvo ausente del avistaje original. Y pese a su cautela, el hecho de no haber entrevistado a este hijo del policía no fue óbice para que Coca apareciese bastante satisfecho, al menos originariamente, con una carta que Camarasa le atribuye a Montero (h), reproducida, aunque no íntegramente, en uno de sus libros ${ }^{16}$. Pero evitar el riesgo de traspiés innecesarios echa luz sobre la importancia de verificar la existencia y veracidad de toda fuente a emplear, lo que podría explicar la decisión de Coca de apartarse de Camarasa. En cuanto a Santander, ni duda cabe que su volumen constituye una muleta de poca solidez. Sería un apoyo menos frágil si éste no hubiese quedado desacreditado por dos minusvalías, difíciles de ser barridas debajo de la alfombra: errores fácticos denunciados por las autoridades germanas, y el origen de buena parte de las extraordinarias alegaciones allí contenidas en una fuente particularmente incierta, Heinrich o Enrique Juerges, formidable falsificador de información suplida a las embajadas de las potencias aliadas en ambas márgenes del Río de la Plata, y también durante la guerra a la Comisión Investigadora de Actividades Anti-Argentinas (CIAAA) de la Cámara de Diputados, que tuvo en Santander a uno de sus legisladores más activos. Tras su deportación de posgue- rra, Juerges se encontró con Santander en Alemania, avituallándolo de información más tarde reciclada, por ejemplo, en ese libro suyo. Si bien esto último dista de verse visiblemente explicitado en el trabajo de Coca, él procura escudarse de falsedades provistas por Juerges. Afirma que «Santander era -cuanto menos- víctima de las operaciones de prensa orquestadas desde la embajada de Estados Unidos» ${ }^{17}$. Decodificado, admite que Santander participó en campañas aliadas de desinformación en Buenos Aires. Tras el triunfo electoral de Arturo Illia, no en vano quizás la propuesta de Santander de un acto conmemorativo de la lucha antinazi de esa CIAAA fue desoída por las instituciones judías a las que éste apeló. Es sólo natural, pues, evaluar los datos de Santander sin ignorar, entre otras cosas, su actuación en el período bélico y de temprana posguerra, tal como lo hizo Coca, a diferencia de los periodistas a los que cita en su pieza.

Con ese trasfondo, resulta poco asombroso que algunas obras de ficción superen a sus contrapartes del periodismo investigativo local en su apego a realidades bastante bien documentadas. Sin ser ese un requerimiento de tal género, piénsese, por caso, en la fina ironía del escritor y cineasta argentino Alejandro Agresti, no ya en la elección de título para su nove-

\footnotetext{
${ }^{16}$ Camarasa, Puerto seguro, pp. 171-174.

${ }^{17}$ Coca, p. 19.
} 
la más reciente, sino al permitir que uno de sus personajes -el líder de una comunidad alemana que resguarda posiblemente a criminales de guerra nazis- se mofe de la actitud acrítica de parte del público respecto de historias forzadas sobre submarinos del Tercer Reich aquí. Al habilitar a ese personaje a instalar la duda de si los restos de algún sumergible germano podrían estar en el fondo de un lago de una localidad bonaerense, quizás secretamente conectado al marr $^{18}$, Agresti impensadamente ilustra el potencial de la literatura, que según el escritor argentino Mario Goloboff es la única ficción que sin negar su carácter, "puede rodear, puede abarcar, puede arrojar nuevas luces (aun entre nuevas dudas) sobre los fenómenos colectivos» ${ }^{19}$. Aquí la ficción de Agresti ilumina que las exageraciones sobre los submarinos alemanes y la afluencia de nazis puede terminar alentando, principio de acción y reacción mediante, la minimización de su importancia.

Vistos los efectos nocivos arriesgados por tales exageraciones, corresponde ilustrar mejor el celo por ajustarse a los hechos de algunas novelas y textos periodísticos, y más específicamente el paradójico contraste entre ciertas ficcionalizaciones escrupulosamente apegadas a la historiografía, y aquéllas investigaciones periodísticas que no se han privado de incursiones en el terreno de la fantasía. Así, por caso, el novelista argentino Daniel Sorín narra con mano firme el reclutamiento y actuación de Ronald Richter, abusador de la confianza que Perón había depositado en él, siguiendo de cerca a la bibliografía científica. Ello puede constatarse fácilmente acudiendo a los trabajos de físicos e historiadores que investigaron el proyecto nuclear argentino. Beneficiario de la impericia del contratante y de la cultura del secreto local, Richter llegó a poner a Perón en un serio brete: poco atractiva para un político, la posición de quien ha sido persuadido, aunque sea temporalmente, por el «palabrerío de un charlatán aprovechándose de la ignorancia del emperador $\aleph^{20}$.

\footnotetext{
18 Alejandro Agresti, Eva Braun de Arroyito, Buenos Aires, Planeta, 2010, p. 235.

19 Página/12, 28/04/11. Que ese potencial de la literatura también puede verse mal aprovechado es ilustrado, por caso, por un escritor argentino y otrora militante comunista. No ser más seguidor de Vittorio Codovilla, catalogador del movimiento construido por Perón como «naziperonismo», no significa en este caso haberse librado de esas equiparaciones del peronismo con el nazismo: tal es el caso de la referencia a la Sección Especial de la policía de Perón y su jefe como equivalentes criollos de la GESTAPO y Himmler respectivamente. Tampoco pudo este autor superar la noción caduca de que la afluencia de nazis acontecía para que «los hijos y nietos de los SS (...), confiados en que vivirán la hora de la revancha», puedan gestar desde aquí un Cuarto Reich. Andrés Rivera, Kadish, Buenos Aires, Seix Barral, 2011, p. 28; Página/12, 30/06/11.

20 Daniel Sorín, El hombre que engañó a Perón, Buenos Aires, Sudamericana, 2008, p. 207.
} 
Con escasas imprecisiones -por lo general puestas en boca de opositores locales y estadounidenses de Perón, lo cual refleja acertadamente sus creencias $^{21}$-, la obra de Sorín sobre el físico austríaco que se atribuyó experiencias nucleares -de resultados imposibles de replicar, empero-, se aproxima a una reconstrucción biográfica de Richter y los orígenes del proyecto nuclear argentino, escrita por un profesional de la historia, si se la compara con los volúmenes, por caso, de De Nápoli y Camarasa sobre esos recursos humanos del Tercer Reich que fueron atraídos al país en la temprana posguerra.

La llegada de Richter formaba parte del interés en convocar a científicos y tecnólogos europeos, no sólo germanos ${ }^{22}$, para fomentar el desarrollo del país, con abstracción de una infraestructura industrial que, junto a los avatares de la economía argentina, impidió una mejor utilización de los contratados por distintas reparticiones oficiales. Hace tiempo se sabe que ese afán argentino, no sólo de Perón ${ }^{23}$, entró en competición con el de países centrales que se abocaron a la misma caza de esos recursos humanos.

Un título reciente de De Nápoli está dedicado a contados casos puntuales de los 1.100 alemanes y otros no cuantificados científicos y tecnólogos arribados. De entre ellos, optó por un puñado, no todos germanos, en su mayoría tratados antes. Aquí la atención puesta en el premio Nóbel Friedrich Bergius y un profesional danés son acaso lo más novedoso para el lector ceñido al español. Corresponde, empero, hacer la salvedad de que un documento mencionado como "hallado en la biblioteca de la actual Secretaría de Industria», es posible borrador del sumario

\footnotetext{
${ }^{21}$ Sorín, pp. 48, 80.

${ }^{22}$ Robert A. Potash y Celso Rodríguez, «El empleo en el Ejército argentino de nazis y otros científicos y técnicos extranjeros, 1943-1955», en: Ignacio Klich (ed. huésped), Inmigrantes, refugiados y criminales de guerra en la Argentina de la segunda posguerra, número monográfico de Estudios Migratorios Latinoamericanos, año 14, № 43, 1999; Ignacio Klich, «La contratación de nazis y colaboracionistas por la Fuerza Aérea Argentina», en: Ignacio Klich (comp.), Los nazis en la Argentina: política y economía, número monográfico de Ciclos, año 10, № 19, 2000.

${ }^{23}$ Pese a su oposición a Perón, un físico otrora socialista, por ejemplo, primero no sólo recomendó el desarrollo de la energía atómica y la contratación de científicos extranjeros, sino que también se abocó a tratar de lograr aquélla del germano Werner Heisenberg, premio Nóbel a la física y ex servidor del Tercer Reich. Ignacio Klich, «Richard Gans, Guido Beck and the Role of German Speaking Jewish Immigrants in the Early Days of Argentina's Nuclear Project, en Ignacio Klich (ed. huésped), German \& Italian Jewish Scientists in South America, número monográfico de Ibero-Amerikanisches Archiv, año 21, N1-2, 1995, pp. 159-160. (Para una versión más breve de este trabajo, ver Ignacio Klich, «La pericia científica alemana en el amanecer del proyecto nuclear argentino y el papel de los inmigrantes judíos», Boletín del Instituto Ravignani», № 10, 1994).
} 
de lo conversado por Bergius y un Perón recientemente triunfante en las urnas ${ }^{24}$. Reiterativos de anteriores trabajos de estudiosos locales y extranjeros, no siempre claramente acreditados, están, en cambio, los capítulos dedicados a Reimar Horten, Ronald Richter, Kurt Tank y el francés Emile Dewoitine. De Nápoli además encontró irresistible la tentación de incorporar a alguien con credenciales bastante menores cuando se las compara con las de otros, excluidos: se trata de Josef Mengele, conocido como el «ángel de la muerte» del campo de exterminio de Auschwitz.

Tristemente célebre, el infame Mengele es un personaje al que De Nápoli volvió más extensamente en un volumen posterior. A diferencia del primero, éste está parcialmente construido a partir de conversaciones suyas con una conocedora de los crueles experimentos del «ángel de la muerte» con cobayos humanos en Auschwitz. Reales o ficticias, esas pláticas le sirven a De Nápoli para deslizar, entre otras cosas, juicios adversos sobre his- toriadores del fuste del británico Hugh Trevor-Roper y el ya aludido Newton, como si éstos no hubiesen sido más que alfeñiques $^{25}$. Carente de originalidad, De Nápoli repite miméticamente el intento previo de Camarasa de retratar a Newton como fuente de simplificaciones y absur$\operatorname{dos}^{26}$. Tomados en conjunto, este par nos recuerda el ilusorio anuncio de 1951 sobre el salto en materia nuclear alegadamente dado por el país. Mal aconsejado -posiblemente porque el consejero, Richter, carecía de trabajos académicos publicados, entre otras falencias que se hacían notar con fruición entre científicos excluidos del proyecto, con el físico argentino Enrique Gaviola a su cabeza, así como entre políticos opositores-, Perón habría empequeñecido a esas publicaciones especializadas, supuestamente sorprendido al comprobar que "los más autorizados científicos extranjeros» daban a conocer allí teorías «enormemente alejadas de la realidad ${ }^{27}$. Con su dosis ostensible de desparpajo, y separados por décadas en-

\footnotetext{
${ }^{24}$ Carlos de Nápoli, Los científicos nazis en la Argentina, Buenos Aires, Edhasa, 2008, p. 76. En la nota al pie correspondiente, De Nápoli menciona el hallazgo de una publicación británica, con copia facsimilar de su carátula reproducida en p. 77, práctica que evitó hacer extensiva al borrador de reporte aludido. ${ }^{25}$ Poco modesto, De Nápoli cree poder juzgar declaraciones de Trevor-Roper en inglés como las de un «falsificador», sin detenerse en las implicancias del hecho de tratarse de una lengua que entiende «con alguna dificultad». Para De Nápoli, Newton, en cambio, habría minimizado «la importancia de la República Argentina y de la Patagonia para los nazis» por poseer "grandes limitaciones para comprender los pormenores de la política argentina, y de sus aspectos socioeconómicos y militares». De Nápoli, La fórmula, pp. 147-148, 159.

${ }^{26}$ Camarasa, Puerto seguro, p. 152.

${ }^{27}$ Sorín, p. 66.
} 
tre sí, dos amateurs locales y uno foráneo -De Nápoli y Camarasa, en el caso de la historia, Richter en el de la física nuclear-, se permitieron abrir juicio sobre el trabajo de expertos con mayor pericia reconocida que la suya, como si las respectivas producciones de éstos apenas fuesen detritus intelectuales. Sin ser físico nuclear, Richter era con todo, vive la petite difference, un profesional de la física. Ya se verá, en cambio, cuán difícil sería intentar sostener que De Nápoli y Camarasa son profesionales de la historia.

Pese a que De Nápoli se arroga el descubrimiento de una «infinidad de documentos», puede confirmarse que ninguno, todos insuficientemente bien individualizados, procede de alguno de los repositorios argentinos o foráneos con mayor densidad de materiales sobre tales científicos y tecnólogos. Asimismo, resulta curioso que De Nápoli omita presentar siquiera un registro en apoyo de su retrato de Mengele como «el maestro de maestros en la experimentación con productos de toda naturaleza ${ }^{28}$. No es que Mengele jamás sometiera a experiencias brutales con una panoplia de recursos a innúmeros deportados a Auschwitz. «Maestro de maestros», empero, es un superlativo que sin titubeos no le cabe. Tratándose de una etiqueta disparatada, no sorprende la penu- ria de evidencia al respecto, sin ser ésta la única instancia en que una afirmación de De Nápoli aparece absolutamente exenta de probanza. Resulta innegable que tales aseveraciones conforman una realidad que le cuadra mejor a una obra de ficción, no a una investigación periodística. Y, dicho sea de paso, no se requiere de una filiación peronista o simpatías pronazis para notar que la dificultad para anudar a la documentación la sobrevalorada importancia de Mengele de ninguna manera lo escudaría de las denuncias de crímenes sumados en su contra.

Con la poquedad de los casos abordados por De Nápoli como trasfondo, la entendible inclusión de Mengele entre los tratados por él, sin embargo, es fácilmente descifrable. Está encaminada a sugerirle tres cosas, si no más, al lector insuficientemente bien informado:

1. En términos cuantitativos, los verdaderos científicos y tecnólogos germanos empleados por Argentina serían relativamente escasos, siendo gran parte del total de los ingresados bajo esa rúbrica los que acompañaron en primer lugar a «la hez de burócratas, asesinos y trastornados humanos de la guerra $»^{29}$. Contrariamente a ello, empero, la contratación de más de un millar dista de ser un número menor. 2. En términos cualitativos, los verdade-

28 De Nápoli, La fórmula, p. 13.

29 De Nápoli, La fórmula, p. 81. 
ros expertos -aquéllos que buscaban convertir al país en un émulo del Reich, repitiendo, "adecuados a la realidad argentina, los planes cuatrienales del nazismo» ${ }^{30}$ eran sobre todo quienes fueron desechados por las potencias. Un mero científico «del montón» es como De Nápoli catalogó, por caso, a Richter. Más tarde, empero, quedó demostrado lo incorrecto de etiquetar a todos en el lenguaje coloquial del outlet como mayormente técnicos y científicos "de segunda selección»" ${ }^{31}$ : tras la caída de Perón, de 110 germanos que trabajaron para el nuclear y varios proyectos militares argentinos, cerca del $40 \%$ se mudó a distintos países centrales, contratados para continuar con su labor profesional.

3. Los desembarcados en Buenos Aires, cuando no sirvieron como señuelo para alejar posibles sospechas de los criminales de guerra a los que venían acompañando, sencillamente pertenecían a esa categoría. En palabras de De Nápoli, es «un hecho histórico innegable» que entre los "miles» de criminales nazis en Argentina, muchos «fueron traídos al país oficialmente como científicos» ${ }^{32}$. Cierto es que algunos criminales ingresaron como mano de obra calificada, o incluso mejor preparada: Mengele, por caso, llegó como mecánico; Adolf Eichmann, como técnico/mecáni$\mathrm{Co}^{33}$; otros europeos, afectados al proyectil teledirigido que se intentaba desarrollar con tecnología alemana, carecían de experiencia científica o ingenieril para tal proyecto, suponiéndoselos fugitivos políticos de Europa, y, de estar algo inspirado en la realidad, el comandante de un ghetto en el que estuvo encerrada un personaje de la ya citada novela de Agresti vino "haciéndose pasar por ingeniero aeronáutico» ${ }^{34}$. Nada de lo antedicho legitima considerar al total de los científicos y tecnólogos contratados por Argentina como cómplices o equivalentes de Mengele, en sentido literal o figurado. Tampoco habilita a ignorar un capítulo nada edificante de la historia argentina: la excesiva facilidad con que se aceptó a quienes distaban de haber sido simples técnicos.

Va de suyo que De Nápoli no fue el único interesado en destacar a Mengele y, por

30 De Nápoli, La fórmula, p. 134.

${ }^{31}$ De Nápoli, La fórmula, pp. 81-83.

32 De Nápoli, Los científicos, p. 139. «Miles», es un conteo abultado que no está apoyado en evidencia más sólida que declaraciones ligeras, por caso las del cazador de nazis Simon Wiesenthal.

${ }^{33}$ En su documento de viaje, Eichmann aparece como técnico, pero los datos que tenía preparados para las autoridades argentinas lo mencionan como mecánico. Neal Bascomb, Hunting Eichmann: How a Band of Survivors and a Young Spy Agency Chased Down the World's Most Notorious Nazi, Boston, Houghton Mifflin Harcourt, 2009, p. 74.

${ }^{34}$ Agresti, p. 122. 
su intermedio, en homologar al brainpower del otrora Tercer Reich a los criminales de guerra afincados aquí. Camarasa también se ocupó del «ángel de la muerte» al concentrarse en su persona dos identidades compatibles, si bien inicialmente distintas: la del profesional y la del criminal. Mucho antes de que Camarasa y De Nápoli, entre otros periodistas argentinos, descubrieran el potencial de tal homologación para desacreditar la captación argentina de especialistas, tan afín a la aliada y de otros países neutrales del período bélico, la equiparación del científico y tecnólogo con el criminal de guerra fue iniciada por algunos de los gobiernos con los que Perón competía, en particular los otrora aliados. Y fue seguida, sin duda, por quienes como Wiesenthal armonizaron la caza de criminales de guerra con su trabajo transitorio para la inteligencia israelí sobre especialistas alemanes involucrados en proyectos militares del mundo árabe, principalmente en Egipto y Siria. Éstos fueron convenientemente retratados por Israel y sus soportes como asistiendo, por caso, al entonces gobernante egipcio a concluir el genocidio iniciado por Hitler, sirviendo los dichos de Wiesenthal para criminalizar a priori a todo científico y tecnólogo del ex Tercer Reich. Así las cosas, la captación argentina de mano de obra altamente calificada fue caricaturizada, lejos de toda ingenuidad, como si se tratase de criminales en principio.

En cuanto a Camarasa, su interés en Mengele se tradujo en un volumen falto de toda referencia documental o historiográfica, salvo los escasísimos autores, sin mención de las obras de su autoría, que aparecen en el texto. De tomarse nota que se trata de un opus en el que Camarasa además obvió presentar una bibliografía, pese a lo novedoso de su planteo, estamos nuevamente frente a prácticas afines a las de autores de obras de ficción. Incluso Basti, en su ya aludida guía turística, optó por brindar un extenso listado bibliográfico. Cualquiera el provecho extraído por este último de los títulos de consulta y otros que publicita, conviene aclarar que la de Basti es una lista muy mezclada, al igual que la más extensa publicitada en su título más reciente sobre Hitler aquí, con obras de historiografía cuidadosamente documentadas colocadas al lado de ensayos fantasiosos carentes de toda base seria. Por otra parte, es llamativo el desconocimiento que Basti demuestra tener de trabajos muy rigurosos en el análisis y densos en lo que se refiere a las fuentes, con abundante aporte de pruebas que destruyen su versión sobre el final del nazismo. No asombra, por tanto, que Basti crea poder demostrar que «lo cierto es que Hitler escapó» en avión a Austria y España, y de allí a la Patagonia en submarino, asesinándose antes a uno de sus alegados do- 
bles para dejar en el búnker en Berlín un cadáver que engañara a los soviéticos ${ }^{35}$. Y tamaña conspiración se logró gracias a un «acuerdo» secreto de la dirigencia nazi con Washington, "probable» beneficiario de ayuda técnica germana para su proyecto nuclear, y la escasamente inesperada complicidad del gobierno militar argentino.

Comparada con Basti, Camarasa y De Nápoli, en particular la forma de encarar sus respectivas investigaciones, una obra del mismo género, de autoría mexicana, es desde el punto de vista metodológico eminentemente superior. En ésta, el periodista Juan Cedillo se ocupa del vínculo bilateral mexicano con Berlín, sobre todo antes del quiebre de relaciones con el Tercer Reich, que convirtió a México en uno de dos aliadófilos beligerantes latinoamericanos. En años previos al corte, el Tercer Reich había visto a México como una fuente de abastecimiento de petróleo. Y Cedillo se abocó al tema recurriendo a los inagotados y acaso inagotables registros acopiados por los National Archives estadounidenses ${ }^{36}$. Pese a evitar hacerle injusticia a Cedillo con un comentario apretado de su obra aquí, ni duda cabe que distinto habría sido la resultante de su quehacer de haber preferido éste lamentarse por los «miles y miles» de papeles inaccesibles, dejando de investigar en los existentes. El paréntesis abierto permite concluir, pues, que el apego a la documentación de De Nápoli, Camarasa y Basti no sólo es deficitario, por caso visà-vis un autor de obra de ficción como Sorín, sino también respecto de este investigador periodístico mexicano. No es ocioso concluir, por tanto, que el cuestionamiento a estos autores argentinos dista de estar inspirado en una noción desdeñosa del periodismo investigativo en general como una forma de charlatanería.

A propósito de las omisiones en el libro de Camarasa, ellas no logran su cometido si éste era evitar que el lector menos bien informado identificara los empréstitos de terceros irreconocidos. Incluido entre los reconocibles, por caso, se halla el estadounidense Ira Levin. Con justicia, su novela Los niños del Brasil es de los textos que deberían encontrarse en un listado de reconocimientos de Camarasa, al haberle servido de manera irrebatible como fuente de inspiración aquí ${ }^{37}$. Basada en lo que se

\footnotetext{
35 Basti, El exilio, p. 181. Sobre Hitler y sus supuestos dobles, Basti se resiste a extraer las conclusiones a sacar de una realidad bien simple: jamás se identificó a tales dobles, sea durante o después de la guerra.

36 Juan Alberto Cedillo, Los nazis en México, México D.F., Debate, 2007.

37 Al igual que lo sucedido con la novela de Levin, Camarasa tampoco menciona que un párrafo entero de su libro -palabra por palabra, y coma por coma- proviene, por ejemplo, de un artículo del periodista Ricardo Ayestarán Fajardo. La evidencia del manoteo al patrimonio de Ayestarán está a la
} 
conocía sobre las experiencias de Mengele para mejorar la reproductividad aria, la obra de ficción de Levin lo presentaba habiendo gestado en Brasil cerca de un centenar de clones de Hitler, gracias a la sangre y espécimen de su piel que éste había dejado. Desde ese ángulo, la historia de Mengele intentada por Camarasa se ocupa de manera preferente de ligar su labor sudamericana, en particular aquélla en Brasil, con sus experimentos en Auschwitz.

Camarasa informa que desde el arribo de Mengele a Brasil, a comienzos de la década de 1960, se observó una explosión de nacimientos de mellizos y gemelos en la localidad de Cándido Godoi e inmediaciones. Al parecer insatisfactoriamente dilucidada, ésta se volvió un verdadero desafío para Camarasa. Sin evidencia científica que apuntale el edificio que ensaya construir, él trata de basar una explicación creíble de esa proliferación de dúos en la actividad previa de Mengele, tanto europea como sudamericana, centrando esa explicación en la experiencia acopiada en Auschwitz $\mathrm{y}$ con productores pecuarios argentinos $\mathrm{y}$ paraguayos, respectivamente deseosos de acrecentar las crías de su ganado.
Claro que la existencia y éxito de la labor de "conseguir que las vacas le parieran terneros mellizos, primero en Buenos Aires y después en el Paraguay» puede que también pertenezca al mundo de la fantasía $^{38}$. Entre los antecedentes ilustrativos de la propensión de Camarasa a lo imaginario se encuentran, como primer ejemplo, su errónea adjudicación de la agregaduría militar del Tercer Reich a Johannes von Leers - grueso yerro mediante, desdoblado en dos Von Leers con idéntico nombre de pila, uno un diplomático inexistente aquí, el otro un verdadero publicista nazi-, y la también equivocada presentación de los documentos de identidad para prófugos y otros ex nazis que Adolfo Savino llevó a Europa en la posguerra como alegadamente enviados durante el período bélico por Perón a Heinrich Himmler a través del ilusorio Von Leers diplomático y/o Alberto Vignes, por sólo mencionar algunas falacias publicitadas y dejadas sin enmendar por este autor ${ }^{39}$. Resulta escasamente extraordinario, por tanto, que no se sepa específicamente "de una posible actividad ganadera» de Mengele en el par de Estados conosureños en los que vivió antes

vista en una publicación montevideana que data de casi cuatro años antes de que ese texto apareciese exactamente reproducido, pero sin entrecomillado o reconocimiento del empréstito, en este libro de Camarasa. Cotejar Jorge Camarasa, Mengele. El ángel de la muerte en Sudamérica, Buenos Aires, Norma, 2008, p. 109, con Ricardo Ayestarán, «La fuga de los nazis y la ruta de los monasterios», Informe Uruguay, 03/12/04.

${ }^{38}$ Camarasa, Mengele, p. 184.

${ }^{39}$ Ver Ignacio Klich y Cristian Buchrucker, «El fin del Tercer Reich», pp. 284-291. 
de mudarse a Brasil. Tampoco parecen ser particularmente deseables los partos de mellizos en vacas, por el mayor esfuerzo de la madre y menor kilaje de los terneros, requeridor este último de alimentación suplementaria, además de la superación de otros trastornos posibles para una y otros ${ }^{40}$. En este sentido, Camarasa emuló al menos improvisado de sus pares argentinos, Uki Goñi. Aceptó como irrefutable una declaración no evaluada, recogida en entrevista con Perón por el periodista y novelista argentino Tomás Eloy Martínez, cuyos innegables méritos en esas labores sólo pueden palidecer, por supuesto, al aplicarse a otros terrenos, por caso a la historia en general y su incursión en la de Perón y los nazis en particular. Pese a ser Argentina un país donde la ganadería es importante $y$, por ende, la pericia sobre el particular nada insignificante, no pocos autores locales documentaron esos lazos de Perón, con Mengele en particular, a partir de lo publicitado por Martínez, autor, que según dos otrora investigadores de la CEANA, se ocupó de realzar «la ostensible asociación del primer peronismo y los nazis» ${ }^{41}$.

Nada de lo antedicho significa ignorar las diferencias entre Levin y Camarasa. Anterior a la muerte de Mengele, la no- vela se concentra en su búsqueda por un tal Yakov Liebermann, cazador de nazis inspirado en Wiesenthal, que sin embargo se mostró hipercrítico del narrador estadounidense. Con excedida dureza, Wiesenthal dictaminó en 1977 que ésta era una obra de "ficción demencial» ${ }^{42}$. Quizás, esa negatividad sea explicable por su interés en una explotación más eficaz de este recurso publicitario, tal como él ya había logrado hacerlo con la ODESSA de Frederick Forsyth para dar en Argentina con un ex comandante del ghetto de Riga, Eduard Roschmann. También ayuda a explicar la postura de Wiesenthal su solitaria forma de operar. Con ese rasgo en mente, no es ocioso imaginar su desagrado al verse retratado en la novela buscando capturar a Mengele con ayuda de Meir Kahane -precursor ideológico de los proponentes ultranacionalistas del expurgue de la ciudadanía palestina de Israel-, si bien las simpatías del cazador para con la derecha del arco político hebreo, más que acercarlo a los líderes laboristas de todas las coaliciones de gobierno israelíes hasta 1977 , tendían a empujarlo hacia Kahane. Finalmente, la explicación buscada debe incluir que Levin no lo consultó antes. Todo esto permite preguntar-

\footnotetext{
${ }^{40}$ Heinz Schneppen, «De todas las Odessas, aquélla de Perón», en: Ignacio Klich y Cristian Buchrucker, Argentina y la Europa del nazismo, p. 217.

${ }^{41}$ Leonardo Senkman y Saúl Sosnowski, Fascismo y Nazismo en las letras argentinas, Buenos Aires, Lumiere, 2009, p. 128.

42 Tom Segev, Simon Wiesenthal: The Life and Legends, Nueva York, Doubleday, 2010, p. 332.
} 
se si, de conocer Camarasa la reacción de Wiesenthal, su afinidad con él y el centro que lleva su nombre explicarían su asombroso desconocimiento de Levin.

Comoquiera, cabe pensar que, junto al enojo de Wiesenthal y aclaración de Levin que todos sus personajes eran «imaginarios y no se pretende representar con ellos a ninguna persona viva $»^{43}$, este thriller llevado a la pantalla cumplió un papel, aun si fallido, en la búsqueda de Mengele. Posterior a su muerte, el libro de Camarasa, en cambio, se sirve de Mengele para presentar su versión personal del derrotero de más de un criminal nazi en Sudamérica, en particular éste. Y, al no tratarse de una obra de ficción, la supuesta liaison entre él y los mellizos que Camarasa imagina quedó ampliamente desacreditada por el diario de Mengele, que lo ubica en Brasil, sólo que a gran distancia de Cándido Godoi. Esa liaison fue también desestimada por colegas anglosajones de Camarasa, pese a su etiqueta de «asesor» del Centro Wiesenthal de Los Ángeles, tal como Santander había asistido a Wiesenthal en Viena, en publicaciones de divulgación científica, entre otras ${ }^{44}$.

Más importante para nuestro trabajo, son las conclusiones a extraer de las coincidencias de Camarasa y De Nápoli sobre Mengele ${ }^{45}$. Con afinidad a la fantasiosa sobrevida de Hitler de la que De Nápoli, a diferencia de Camarasa, no logra desacoplarse, éste también cuestiona la muerte de Mengele en Brasil. En sus palabras, ésta fue «otra maniobra de los alemanes para sacarlo de la escena», habiendo Mengele en realidad huido, «hacia ignoto lugar» ${ }^{46}$. Sin soporte documental, pero basado en

43 Ira Levin, Los niños del Brasil, Barcelona, Pomaire, 1978, p. 7.

${ }^{44}$ Daily Mail, 23/01/2009; New Scientist, 27/01/2009.

${ }^{45}$ Subrayar las semejanzas no significa ignorar las diferencias entre De Nápoli y Camarasa. Su disenso, por caso, es visible en lo tocante a la reacción en Buenos Aires al pedido de extradición de Mengele. Este fue presentado por Bonn en septiembre de 1959 y concedido en junio de 1960, semanas después de capturado Adolf Eichmann. De acuerdo con De Nápoli, «a nivel mundial, se generó la impresión de que la República Argentina lo había protegido (a Mengele), pero en este caso todo resulta falso. La justicia local, caso extraño, actuó con presteza». En su lugar, Camarasa denuncia las «chicanas jurídicas» con las que «Argentina sumaba dilación», presentándolas como parte de un dechado de «lentitud judicial», y retrata a Mengele como beneficiario de tal actitud argentina. Camarasa extiende las presuntas falencias de la cancillería y poder judicial a las fuerzas armadas también, en especial a un alto oficial de Ejército. Aunque no lo deletree, el relato de Camarasa permite inferir que de haber contado Eichmann con la misma benevolencia castrense que le adscribe a Mengele, el primero tampoco habría sido apresado por Israel, vale decir que Eichmann carecía de las conexiones del ex «ángel de la muerte», y las que tenía facilitaron su eventual captura, y participaron luego en la fallida cacería de Mengele. De Nápoli, Los científicos, p. 131; Camarasa, Mengele, pp. 84, 86, 108.

46 De Nápoli, Los científicos, pp. 139, 142. 
un «historiador riguroso del Holocausto", en referencia a una aguerrida víctima del nazismo - publicista sin par, pero difícilmente un historiador tal, a juzgar por su nombre definitivamente inexistente en bibliografías de profesionales de la historia que se ocuparon del genocidio nazi-, Camarasa comunica que

«Mengele murió en Estados Unidos en 1992, mientras era protegido por la CIA, y que la rumorosa descubierta de sus restos a fines de 1985 en un cementerio de los alrededores de San Pablo no sería otra cosa que una farsa internacional montada por los Estados Unidos y aceptada por Israel bajo presión».

Con mayor timidez, Camarasa también admite, a continuación, la muerte de Mengele «a fines de los años setenta». Esa ida y vuelta es reiterada al señalarse más tarde indocumentados «reparos» israelíes sobre la certificación de forenses germanos y estadounidenses a propósito del ex «ángel de la muerte», más extensamente explicitados que su tímida alusión suplementaria al fallecimiento de éste en la década de 1970. Los conocedores de la bibliografía encontrarán un antecedente de esta rutina en el mismo proceder de Goñi en relación a los restos exhumados de Bormann ${ }^{47}$.

Los alegados «reparos» hebreos ameritan atención suplementaria: el informe sobre Mengele de la unidad criminales de guerra de la policía israelí desmiente a Camarasa. En vez de claras reservas oficiales, ese documento revela que, luego de exhumados los restos de Mengele, las radiografías aportadas por su dentista en Brasil permitieron identificarlos "con absoluta certeza" como pertenecientes a él ${ }^{48}$. ¿A quién se refería, pues, Camarasa? Muchísimo mejor documentado por lo general, así como más escrupuloso y profesional, el historiador hebreo Tom Segev, autor de la primera biografía de Wiesenthal basada en documentación de su archivo personal y otros repositorios, anotó sobre la muerte de Mengele que este infatigable cazador «encontró difícil rendirse (ante la evidencia). Cuatro años después de la identificación de sus restos, todavía se aferraba a ciertas dudas, pero ya nadie le creía. Mengele estaba muerto y la confiabilidad de Wiesenthal había sufrido un severo golpe» ${ }^{49}$. Si bien posteriores al libro de Camarasa, las afirmaciones del autor israelí coinciden con lo que ya se conocía a partir de los registros odontológicos de Mengele, y más aún cuando sus restos se vieron sujetos en 1992 a las pruebas de $\mathrm{ADN}$.

\footnotetext{
${ }^{47}$ Camarasa, Mengele, pp. 139, 166, 179, 187.

48 Haaretz, 30/04/2011.

49 Segev, p. 339.
} 
En resumen, al no estar avalados por pronunciamientos en ese sentido de funcionarios de gobierno y/o instituciones oficiales hebreas, los antes aludidos «reparos» israelíes no parecen haber sido más que aquéllos de Wiesenthal, y de otros como él. Y altamente encomiable como lo es en general, la cautela de Camarasa respecto de la muerte de Mengele-actitud que por cierto resultaría más creíble de haberse podido verificar que siempre lo guió en su labor- sólo refleja de manera inmisericorde la claque que éste intenta aportarle a un Wiesenthal renuente a reconciliarse con una realidad singularmente adversa: el cazador entendía las crueles implicancias de su fracaso, al no figurar Brasil entre los países donde había dicho que Mengele se hallaba, y al haberse hecho acreedor el dictador guaraní Alfredo Stroessner a una disculpa suya, jamás ofrecida, por confirmarse cierta su afirmación que Mengele, privado de la ciudadanía paraguaya que supo disfrutar durante dos décadas a partir de 1959, no se hallaba en ese país desde largos años atrás. Todo esto es ajeno a Camarasa, que, más leal a Wiesenthal que a la historia, procura dejar la puerta entornada para más especulaciones acerca de un Mengele superviviente.

Con mayor o menor grado de sutileza, está claro, por tanto, que las alegaciones de De Nápoli y Camarasa procuran sem- brar dudas sobre la muerte del ex «ángel de la muerte» en 1979 en el estado de San Pablo, a sabiendas de que «la duda es más corrosiva que cualquier certeza ${ }^{50}$. Aquí, por supuesto, el común denominador entre ambos es una evidente falta de carnadura para poder cuestionar los resultados del examen de ADN. Lejos de hacer un alto ante tamaña calamidad para sus hipótesis, este par decidió que la carencia de pruebas que permitan contradecir esos resultados podía superarse gracias a la política del avestruz: ignorando tal aporte de la medicina forense. La misma falta de evidencia tampoco fue óbice para que uno y otro sugirieran veladamente un complot alemán, con o sin connivencia de Washington u otros, para mostrar a Mengele como fallecido hace tiempo, resguardándolo así de sus buscadores. En marcado contraste con otros, De Nápoli y Camarasa también evitan tratar seriamente el fracaso de Wiesenthal respecto de Mengele y otros criminales, y las enseñanzas que se desprenderían de ello.

Menos timorato al respecto que De Nápoli y Camarasa, Segev anotó que en el año de la muerte de Mengele, que desafortunadamente pasó inadvertida para quienes querían verlo enjuiciado, Wiesenthal podía consolarse pensando que el malestar que ello le producía también aquejaba a otros: «el Mosad israelí y el fiscal alemán

50 Sorín, p. 38. 
Fritz Bauer no habían sido más exitosos que él $»^{51}$. Naturalmente, desde entonces ese cuadro sólo pudo mantenerse inalterado. Tampoco le rehuye Segev al apareamiento del fiasco en torno al ex «ángel de la muerte» con otros, por caso con la más fútil búsqueda de Bormann, muerto desde fines de la guerra, con cuyos restos hallados en Berlín en los primeros años de 1970 el cazador recién se reconcilió más de dos décadas después. Además, a diferencia de De Nápoli y Camarasa, Segev alude, al igual que otros antes que él, a múltiples declaraciones falaces de Wiesenthal. En el marco de una biografía escrita con evidente simpatía hacia el biografiado, tratando de entenderlo con magnanimidad e incluso justificarlo, o acaso defenderlo por momentos a capa y espada, Segev, empero, se abstiene de barrer bajo la alfombra elementos críticos sobre é $\mathrm{e}^{52}$. Con trazo fino, presenta a Wiesenthal como un hombre de «ego empinado» y con «una tendencia a fan- tasear» ya insinuada en el título del volumen: The Life and Legends (Vida y leyendas $)^{53}$. Lejos de buscar desmerecer su trayectoria, Segev ilustra la anterior caracterización con un vasto surtido de fábulas -ubicadas en forma dispersa a lo largo del libro, acaso para amortiguar su impacto-, muchas destinadas a mantener el nombre de distintos criminales sobre el tapete, sea para lograr su detención, para promover la toma de medidas reclamadas por Wiesenthal a distintos gobiernos afectados, o bien para reclutar donaciones para su centro de documentación.

Tal como ya lo habían revelado otros antes, Segev confirma, por caso, que «emitidas de tanto en tanto, las declaraciones de Wiesenthal sobre Mengele eran incorrectas, y él lo sabía ${ }^{54}$. También subraya que en materia "de manipulación de los medios, pocos podían medirse con él», si bien los resultados de su modus operandi no siempre terminaban siendo los deseados ${ }^{55}$. No asombra, pues, que

51 Segev, p. 333.

52 Pese a reflejar elementos de su personalidad y performance que son adversos a Wiesenthal, la generosidad de Segev para con él -tal como lo refleja esta biografía «altamente simpática», en palabras de la historiadora estadounidense Deborah Lipstadt- no siempre ha sido bien recibida por los reseñadores, en particular por los que habrían deseado una obra más laudatoria. Ver, por caso, Ron Rosenbaum, "Self Made Golem», Tablet, 02/09/10; Deborah Lipstadt, The Eichmann Trial, Nueva York, Nextbook, 2011, p. 206.

53 Segev, p. 7.

54 Ignacio Klich, «El ingreso a la Argentina de nazis y colaboracionistas», en: Ignacio Klich y Mario Rapoport (eds.), Discriminación y racismo en América Latina, Buenos Aires, GEL, 1997, p. 427, n. 88; Segev, p. 339.

55 Segev, p. 289. 
luego de su anuncio de los años ochenta que Mengele, por caso, se ocultaba entre los menonitas del Paraguay, Wiesenthal se viera obligado a tragarse sus palabras, disculpándose por el agravio a esa iglesia ante una rama europea de ésta en la que contaba con simpatizantes. En lo referente a Klaus Barbie, en 1969 declaró tener «informes importantes» sobre el paradero del llamado "carnicero de Lyon»: infelizmente para sus víctimas, «al parecer, no tenía idea alguna, y, tal como lo había hecho más de una vez antes, informó que estaba en Egipto" ${ }^{56}$. No sorprende, pues, que la captura de Barbie en Bolivia y su juicio en Francia fuesen finalmente logros de otros: Beate y Serge Klarsfeld.

Interesa subrayar, empero, que la catalogación de Wiesenthal ofrecida por Segev está apuntalada, entre otras, por una realidad innegable: éste fue, en rigor, el padre de la versión según la cual Eichmann se había comunicado desde Egipto con su familia en 1953. Y gracias a un socio en United Press para gestar tal especie, ésta pasó de los austríacos «a los medios israelíes, y de ahí, vía otra agencia", a tantos otros lugares ${ }^{57}$. Al no escasear otras versiones sobre su presencia en Oriente Medio, sería tendencioso afirmar que la de Wiesenthal fue justamente la que habilitó en 1958 a la embajada alemana, que decía no poder dar con Eichmann en Argentina, a informar que era «más razonable» suponer que estaba «en algún lugar de Oriente Medio" ${ }^{58}$. De hecho, poco después, Wiesenthal sostenía que Eichmann estaba de regreso en Europa. Tampoco cabe ignorar que todas estas suposiciones ayudaron a alejar temporalmente los ojos puestos en Eichmann aquí, si bien hoy se sabe que la inteligencia germana tuvo indicios certeros de su presencia en Argentina desde 1952, y su par israelí desde el año siguiente, sin que las prioridades de una y otra incluyesen determinar su dirección exacta, antesala a un pedido de extradición. Completa este panora-

\footnotetext{
56 Segev, p. 329.

${ }^{57}$ Segev, p. 113.

${ }^{58}$ Pese a las referencias a incontados criminales nazis en Egipto -hasta 7.000 en todo el mundo árabe, según Wiesenthal, cifra que incluye, empero, a (i) quienes llegaron antes de la guerra; (ii) quienes lograron huir de los campos británicos para prisioneros de guerra; (iii) quienes llegaron gracias a la ODESSA y otros- a ser diferenciados de los científicos y tecnólogos con los que Washington buscó acotar la dependencia militar egipcia de la Unión Soviética, por ahora el único criminal comprobado sería Aribert Heim, también conocido como el «doctor muerte» del campo de Mauthausen, paradójicamente buscado por el Centro Wiesenthal con más despliegue mediático que buena información en Argentina y Chile, donde según «fuentes ostensiblemente confiables», el Centro insistía que Heim había estado viviendo. New York Times, 04/02/2009; Segev, pp. 139, 215.
} 
ma beneficioso para Eichmann, la respuesta del Cuerpo de Contrainteligencia Estadounidense (CIC en inglés) a una averiguación austríaca sobre éste: en 1952, la misión del CIC ya no incluía la detención de criminales de guerra, admisión detrás de la que se parapetaba la impronunciable convicción de que su enjuiciamiento «no es más un interés de primera importancia para las autoridades de Estados Unidos». Meses después, la CIA afirmaba que no estando involucrado su país «en la captura de criminales de guerra, y por ende inhabilitada para adoptar un rol activo en este caso», permanecería alerta «a propósito de cualquier información concerniente al paradero de Eichmann para pasársela a las autoridades pertinentes». Luego, sin embargo, la actuación más conocida de la CIA respecto de Eichmann fue persuadir a una revista estadounidense a abstenerse de difundir declaraciones suyas sobre el pasado de Hans Globke, secretario de Estado en el gabinete en Bonn y redactor en 1935 de las leyes raciales del Tercer Reich ${ }^{59}$.

De regreso sobre el muestrario significativamente más frondoso acopiado por Segev, los escasos ejemplos aquí publicitados ya dan una idea de los riesgos corridos por quienes hayan tomado a Wie- senthal u otros como él al pie de la letra. Infortunadamente, empero, no todas las fábulas de este cazador tuvieron como fin lograr la captura de un criminal huidizo. Ello tiende a agravar su invalidez como fuente no necesitada de avales adicionales, antes de volverse utilizable para historiadores y periodistas responsables. La necesidad de convalidar los dichos de Wiesenthal es tanto mayor cuando ingresa al ruedo el registro de Segev, que este cazador también podía desapegarse de los hechos «adrede». Su dilatado ego efectivamente exacerba la imperiosa necesidad de corroboración, tal como lo ilustran los siguientes casos, parte de un conjunto más nutrido.

En sintonía con una sinopsis autobiográfica suya de 1947, Wiesenthal le hizo creer a la autora de una biografía anterior, entre otros, que había estado en Auschwitz, campo en el que con ajuste a los hechos no estuvo, si bien debió haber sido deportado allí. Al decir de Segev, entonces, «su intento de situarse en el centro de la catástrofe -Auschwitz- fue parte de un patrón fijo, una propensión a magnificar su terrible experiencia». Y en sus libros «tendió no sólo a dilatar su tragedia, sino también a agregarle un pellizco de drama a las circunstancias de su supervivencia ${ }^{60}$.

\footnotetext{
${ }^{59}$ Robert Wolfe, «Did CIA Really Cold-Shoulder the Hunt for Adolf Eichmann?», Interagency Working Group Research Paper, NARA; Richard Breitman \& Norman J. W. Goda, Hitler's Shadow: Nazi War Criminals, U.S. Inteliigence, and the Cold War, Washington, NARA, 2010, p. 13.

${ }^{60}$ Segev, pp. 395-396.
} 
A veces, Wiesenthal hasta se autorretrató como "combatiente en una unidad partisana, con el rango de mayor inclusive, y habiendo operado una radioemisora clandestina y publicado un diario", características ficticias todas ellas que, sin ser poca fábula, merecen ser comparadas con el conocimiento inequívoco de Asher Ben Natan, ex director del Ministerio de Defensa de Israel y primer embajador hebreo en Bonn, de un pasado encubierto por el cazador, bastante menos glorioso.

En la temprana posguerra, Ben Natan fue de los enviados sionistas que alentaron a Wiesenthal, entre otros, a ocuparse de los criminales nazis, antes de que la inminente creación del Estado hebreo llevara a su futura conducción a concentrarse en otros menesteres. "No tengo dudas de que Wiesenthal trabajó para el Judenrat en Lvov», dijo Ben Natan al ser entrevistado por Segev, prefiriendo guardarse para su coleto interno la evidencia sustentadora de un juicio expresado en términos tan categóricos sobre Wiesenthal colaborando con los nazis ${ }^{61}$. Más adelante, Segev cita a Eli Rosenbaum, director de la Oficina de Investigaciones Especiales (OSI, su sigla en inglés), rama del Ministerio de Justicia estadounidense a cargo de nazis y colaboracionistas, subrayando la incapacidad de Wiesenthal de aportar una historia consistente de su trayectoria en el período bélico. ¿Es ésta una alusión velada a lo revelado por Ben Natan? Desafortunadamente para sus lectores, Segev le rehuye a la ligazón explícita del dicho de Rosenbaum con la alegada labor para los comités judíos promovidos por los nazis en los ghettos, tal como le confiara Ben Natan. No obstante, de existir un nexo entre Rosenbaum y Ben Natan, lo revelado sobre su colaboración con los nazis en Lvov puede todavía haber sido fugaz e intrascendente, tal como lo sugeriría la ausencia de documentación al respecto en los archivos de Polonia y la ex República Democrática Alemana (RDA). Tal vez prematuramente, Segev parece considerar que esa realidad de ambos países, al igual que la aparente inexistencia de un testigo inequívoco de lo revelado por Ben Natan, prueba sobradamente que la colaboración de Wiesenthal con los nazis, algo que sus enemigos políticos ensayaron probar en distintas ocasiones, jamás existió. Naturalmente, esta interpretación posible sería insuperable de estar fehacientemente explicado el objetivo de Ben Natan al haber depositado en Segev esa confidencia descartada sobre Wiesenthal. Lamentablemente para quienes no tomaron recaudos al recurrir a sus escritos para documentar los propios, hay más falsificaciones de peso: sin arte o parte en el secuestro físico de Eichmann, Wiesenthal no 
tuvo empacho alguno en presentarse como uno de sus captores. Sumado al papel detectivesco que sí desarrolló en su búsqueda, incluido un malogrado intento de temprana posguerra para apresarlo, la vocación de protagonismo de Wiesenthal buscó capitalizarse a partir del inicial interés hebreo en distanciar a sus servicios de la captura de Eichmann, presentada como la labor de voluntarios anónimos, ex víctimas del nazismo. En una disertación, Wiesenthal describió vívidamente cómo se había lanzado sobre Eichmann, «abofeteándolo repetidamente, empujándolo a un jeep y participando de su interrogatorio». Al igual que en otras ocasiones, Wiesenthal olvidó mencionar que si alguien le hubiera prestado atención, Eichmann no habría sido aprehendido en 1960 al sostener él el año previo que éste se ocultaba en Alemania. Contrariando este ejemplo asaz colorido de su proclividad a arrogarse lo que con estrictez no le correspondía, Wiesenthal jamás puso un pie en Argentina, habiendo considerado, empero, migrar aquí temprano en los años cincuenta ${ }^{62}$.

Con ese trasfondo, no es casual que a ojos de distintos cognoscenti israelíes, Wiesenthal fuese un "falsario legendario", llegándose a informar en una circular de la cancillería hebrea, distribuida en 1970 a toda la red de embajadas israelíes, que éste «a menudo hace afirmaciones que no puede sustanciar». También "se arroga» la captura de Eichmann, pero "quienes conocen la verdad sobre las operaciones dirigidas a desenmascarar a criminales nazis hablan de la irresponsabilidad de Wiesenthal, surgida de su ilimitada avidez de publicidad y egocentrismo». Puede pensarse, pues, que lo afirmado por Segev acerca de su persona agrandada y Auschwitz también rige para otros tópicos, no cabiendo desescuchar la prudencia recomendada por el historiador israelí: Wiesenthal sólo debe ser leído «con cierta cautela», ya que «no es tarea fácil descifrar sus secretos», siendo sus asertos tan ciertos como inciertos, "al igual que mucho de lo que escribión" ${ }^{63}$.

Pese a antecedentes tan poco auspiciosos para permitirse creer de buenas a primeras lo proveniente de este cazador, y a la impiadosa evaluación de sus logros profesionales por parte de otro funcionario del Ministerio de Justicia estadounidense -reveladora, entre otras cosas, de que no todos los acusados por Wiesenthal eran criminales de guerra para el sistema judicial de ese país- ${ }^{64}$, hay por lo menos dos

62 Segev, p. 326; Lipstadt, p. 206.

63 Segev, pp. 9-11, 247-248.

${ }^{64} \mathrm{Si}$ bien Wiesenthal se autoatribuyó haber impulsado la investigación de unos tres mil casos, de entre los cuales un millar desembocaron en juicios de resultado variopinto, su aporte a la caza de nazis, al 
instancias en las que, paradójicamente, el historiador hebreo desoyó sus propias admoniciones. En vez de recurrir a fuentes mejores, fácilmente accesibles, Segev sucumbió a la narrativa de Wiesenthal, tanto en lo concerniente a la conferencia de Estrasburgo, como a la ODESSA. Lo dicho acerca de la reunión en el hotel Maison Rouge de la capital alsaciana, así como sobre la ODESSA, tiene como prólogo un planteo de Segev, de timbre apologético, que "como hombre con aspiraciones literarias», Wiesenthal tendía a permitirse ciertas licencias: «dejarse llevar por la imaginación, y, en más de una ocasión, a deleitarse con el drama histórico, en vez de apegarse a los hechos puros», aclarándose de manera desfasada que «así como no era novelista, Wiesenthal tampoco era historiador». Sin embargo, de no cuestionarse firmemente la indiferencia de este cazador para con la precisión de lo que presentaba como hechos incontestables, y de evitar sopesarse el daño que su febril imaginación pudo causar, ‘̇acaso no se estaría descuidando el potencial educativo de la causa de traer ante la justicia a los criminales de guerra nazis? De degenerar todo esto en un duelo entre perpetradores y embusteros compulsivos, ¿acaso el logro de ese fin podría salir indemne? La respuesta al primero de ese par de interrogantes es afirmativa, negativa al segundo $o^{65}$, siendo francamente falaz la noción de que hacer hincapié en las imperfecciones a granel de Wiesenthal y su modus operandi es perder de vista que sin éste no habría sido enjuiciada la fracción de victimarios de los judíos que él ayudó a atrapar. No siendo Wiesenthal el único o menos imperfecto de quienes se abocaron a tal fin, ¿por qué olvidar, por caso, a los Klarsfeld -germana ella, francés él-, y al estadounidense Charles Allen? Y sin desdeñar la actividad de nadie, ¿por qué creer que Wiesenthal era irremplazable, y que sin él no habrían surgido otros para ocupar su lugar?

Segev comparte con el lector la versión de este cazador sobre Estrasburgo y sus secuelas, a saber que en la temprana posguerra, cuando trabajaba en Austria para la inteligencia estadounidense, "había visto y copiado, sin retenerlo", un documento sobre esa reunión de líderes nazis

menos en Estados Unidos, fue, a ojos de funcionarios del Ministerio de Justicia de ese país, magrísimo. Tal lo reflejado por Neal Sher, entonces director de la OSI, al escribirle a Wiesenthal en 1990 que «la vasta mayoría de sus alegaciones fueron de escaso valor (...), sin proveer usted a la OSI ninguna evidencia concreta en contra de los individuos culpabilizados en su correspondencia... Ninguna alegación surgida de su oficina ha resultado en una presentación de la OSI ante la justicia». Segev, p. 375. Para una versión más extensa y temprana de la misiva de Sher, ver Guy Walters, Hunting Evil: How the Nazi War Criminals Escaped and the Hunt to Bring Them to Justice, Londres, Bantam, 2009, pp. 383-384.

${ }^{65}$ Segev, pp. 27, 311. 
en la ciudad alsaciana para discutir su supervivencia de posguerra y posible retorno al poder algún día. A juzgar por lo que Segev recogió de Wiesenthal sobre el cónclave, la hipótesis de sus participantes era que ante la derrota del Tercer Reich que se avecinaba, era «necesario asegurarse la disponibilidad de fondos para permitir la huida», es decir el traslado de fugitivos líderes nazis «a refugios seguros mediante la organización ODESSA y otros canales». Se recordará que la ODESSA, supuesta entidad conformada por ex miembros de las SS, habría tenido un rol de primera línea en tales huidas. Y, siempre según la información de Wiesenthal, ésta sería un desprendimiento de otra entidad semejante, Die Spinne (La Araña), con base en la embajada siria en Italia, siendo el cazador uno de los más importantes creyentes y publicistas de su existencia ${ }^{66}$.

No habiendo consultado ese documento crucial, de cuya existencia, sin embargo, no parece dudar, Segev se contentó con la versión de Wiesenthal -su exégesis del mismo-, más que con el original ${ }^{67}$. Del otro lado, la ausencia de tal consulta también le permitió a Segev anotar que después «surgieron dudas sobre la realización de esa reunión", de la misma manera como no existía certeza de que los jerar- cas nazis hubiesen recurrido a la ODESSA para facilitarse su escape, o que la existencia de ésta estuviese probada. Segev asimismo parece haber hecho suya la interpretación de Wiesenthal sobre el general Dwight Eisenhower, comandante militar del esfuerzo aliado en Europa y futuro presidente estadounidense, que habría encontrado interesantes esas «minutas» de la conferencia. Sólo que quienes conocen el documento saben que este cónclave, a diferencia de las supuestas referencias en el mismo a la ODESSA y existencia de la misma, no fue un invento. Tuvo lugar en abril de 1944 en el hotel antes mencionado de Estrasburgo. No conformando el documento las actas de la reunión, éste en todo caso representa un ensamblaje de fragmentos de conversaciones de representantes del Ministerio de Armamentos y Producción Bélica del Tercer Reich con gerentes de nivel intermedio de industrias alemanas con intereses en la Francia ocupada. Preparado por un informante anónimo, antes de ser elevado al Departamento de Estado en Washington, el documento no es minuta alguna de esa conferencia, y ninguno de sus participantes es de los nombrados por Wiesenthal, así como la inexistente ODESSA u otros canales de emigración subrepticia no se mencionan

66 Segev, pp. 119-120, 162-163.

${ }^{67}$ La primera versión castellana de ese registro puede consultarse en «Apéndice documental», Ignacio Klich y Cristian Buchrucker, Argentina y la Europa del nazismo, pp. 355-357. 
allí. La evaluación perfectamente posible de Eisenhower, pues, de ninguna manera evidencia a priori coincidencias suyas con Wiesenthal, en particular con la nómina de participantes que éste le adscribió a esa reunión, o con la ODESSA y demás canales de escape no tratados en el documento. Pese a tales imprecisiones, o quizás en razón de ellas, Segev evita detenerse para tratar en profundidad la importancia de Estrasburgo y la ODESSA en la trayectoria del cazador. En cambio, lanza una hipótesis jamás probada a satisfacción, ni remotamente. Dice que:

«es posible que el documento estuviese fraguado, pero Wiesenthal no habría podido saberlo. Así como creía en la existencia de una central que facilitaba el abandono subrepticio de nazis de Europa, creía en el plan de Estrasburgo para financiar su fuga. En agosto de 1946, publicó un artículo en un diario local en el que informaba sobre el fondo nazi de escape. Lo hizo, dijo, a iniciativa de sus superiores en la OSS (antecesora de la CIA) " ${ }^{68}$.

La realidad, sin embargo, es significativamente distinta: el documento aludido -no la deformación wiesenthaliana de aquél que dijo haber transcripto-, existía y volvió a estar a su alcance. Efectivamente,
Wiesenthal, pudo haberlo consultado, lo que dicho sea de paso es también relevante para los demás interesados en ese registro. Pero ello estaba lejos de ser lo deseado por este cazador, difícilmente ávido de hacerle más mella a su comprometida fiabilidad, aquí desnudando otra de sus penosas distorsiones, ésta a supuestas instancias de sus empleadores estadounidenses. ¿Qué interés podía tener Wiesenthal en admitir que en abril de 1944 no había habido ninguna ODESSA, y que en esa fecha La Araña, entidad de la que la anterior se habría escindido, no podía haber tenido su sede en la embajada siria en Roma, cualquiera el apoyo brindado por El Cairo y Damasco para la reubicación en Oriente Medio de ciertos ex servidores del Tercer Reich? ¿Qué rédito podía esperar del reconocimiento que La Araña documentada en registros estadounidenses surgió en su campo Orr, ligada a las redes de inteligencia creadas en 1948 por un ex agente de seguridad nazi para el CIC norteamericano $^{69}$, y que su sede romana, de haber existido, sólo podría haberse conciliado con Siria independizándose en 1946 y abriendo luego embajadas? ¿Qué beneficio le habría arrojado corregir la nómina de participantes en Estrasburgo? Una cosa era anotar a los asistentes con grafías imprecisas, y otra bien diferente era falsear

\footnotetext{
68 Segev, p. 120.

69 Breitman \& Goda, p. 59.
} 
su identidad, planteando nombres de personajes más destacados en el afán de realzar la importancia de la reunión. Al interior y exterior del documento sobre Estrasburgo, este conjunto de ficciones ayuda a entender porqué Wiesenthal evitó darse por aludido cuando ese registro fue publicado en Alemania en 1985, incluido en una colección compilada por el historiador germano Wolfgang Michalka.

Más significativo desde el ángulo de la eternización de una ODESSA ficticia, empero, fue la inesperada visita de Frederick Forsyth, periodista británico y autor de obras de ficción, "para obtener información de Wiesenthal sobre la organización ODESSA» a la luz de una novela que publicaría en 1972, más tarde filmada. En contraste con su actitud frente a otros autores, el cazador tuvo sus dudas acerca de Forsyth. Estas tenían que ver con que

"casi treinta años después de haber escuchado por vez primera los rumores sobre la ODESSA, y de haberlos convertido en una de las bases de su propia fama personal, tenía buenas razones para temer que Forsyth lo despojaría de la historia y la transformaría en una obra de suspenso, con lo que ya nadie creería que la organización clandestina había existido en la realidad ${ }^{70}$.
De haber estudiado el documento sobre Estrasburgo - un verdadero imperativo a la luz de esta evaluación de la ODESSA-, Segev acaso habría podido enriquecer su identificación de fuentes para las aprehensiones de Wiesenthal con el temor adicional de que un Forsyth hurgador hallase el registro que el cazador decía no haber conservado, y con él verificase las torceduras lisas y llanas que éste le había infligido, quedando asimismo al desnudo los cimientos de arena sobre los que se había erigido la fama wiesenthaliana. De ahí que el cazador se abocara a «la preservación de su propia credibilidad, así como de la historia de la ODESSA». Para ello persuadió a Forsyth a incorporar al ya aludido Roschmann, sargento de las SS y otrora comandante del ghetto de Riga durante parte de 1943, a una trama que lo presentaba como una figura importante de la mítica ODESSA, que lo habría ayudado a llegar a Argentina en 1948, y a incluir un nexo con el conflicto árabeisraelí: miembros de la ODESSA conspiraban para abastecer armas biológicas a Egipto para destruir a Israel ${ }^{71}$.

Antes de la filmación, empero, Wiesenthal debió superar un nuevo desafío. No provenía de Forsyth, sino de una historiadora austríaca, Gertrude Schneider, otrora internada en el ghetto de Riga y autora de 
una tesis doctoral sobre éste. Intentando apaciguar a Schneider, Wiesenthal se sintió obligado a admitirle que los crímenes de Roschmann, tal como surgían de su colaboración con Forsyth, eran «algo exagerados». Acto seguido, deflacionó de un plumazo las muertes causadas por el así motejado "carnicero de Riga" a casi un décimo de los 35.000 judíos mencionados antes. Alegadamente, esta nueva cifra provenía de documentación judicial austríaca. Más allá de lo que pueda inferirse sobre la fiabilidad de Wiesenthal a partir de esta dramática revisión del número «algo» cargado de las víctimas de Roschmann, una quita de casi el $90 \%$, de haber sido éstas en realidad 3.800, en vez de 35.000 , todavía habrían sido demasiadas, 3.800 de más, igual que todos los victimizados por el genocidio nazi, que, cualquiera su número, fueron innecesarios.

$\mathrm{Si}$ en sus intercambios con Schneider Wiesenthal argumentó que lo único importante era que el trasfondo histórico de la ODESSA de Forsyth fuese preciso, sin que correspondiese esperar de un thriller exactitudes históricas, muchos lectores se preguntaron qué parte de la novela podía considerarse histórica. Forsyth no siempre fue claro al respecto, en tanto que Wiesenthal y su centro le brindaron un fuerte respaldo a esta obra de ficción -a tono con la anhelada preservación de su fiabilidad personal y aquélla de la historia de la ODESSA que ya había registrado
Segev-, como si la novela y asertos posteriores del autor estuviesen inspirados en hechos realmente comprobados. Sirva de ejemplo de lo antedicho un revelador registro personal del periodista argentino Alfredo Serra, realizado a resultas de cubrir para un semanario porteño la muerte de Roschmann en Paraguay. Allí Serra anotó el siguiente diálogo telefónico con Wiesenthal, al entrevistarlo sobre el caso:

- SW: No es Roschmann. Alguien murió por él.

- AS: Sin embargo, vimos el cadáver... - SW: La organización (ODESSA) es tan grande que puede disponer de cadáveres de reemplazo. Según mis informantes, Roschmann está en Bolivia.

- AS: Pero hay muchas coincidencias. Los dedos de los pies cortados, por ejemplo.

- SW: Sí, leí acerca de eso en el cable. El dato me confunde porque, para mí, Roschmann no tenía esa mutilación.

- AS: Sin embargo, Frederik Forsyth asegura que sí, y cuenta el caso con detalle. Hace apenas un mes le dijo a una enviada especial nuestra que Roschmann perdió los dedos de los pies por congelamiento. A fines del invierno de 1948, mientras lo llevaban detenido de Graz a Dachau, saltó del tren por la ventanilla del baño. Había mucha nieve, tuvo que caminar varios kilómetros hasta alcanzar una población, y se 
le congelaron los pies. La gangrena, ya irreversible, obligó a un médico a cortarle los dedos. Eso fue en Roma. Un mes después se embarcó en Génova rumbo a Buenos Aires.

- SW: ¿Qué archivo consultó Forsyth para conseguir esos datos?

- AS: Los archivos británicos.

- SW: Hummm... Entonces es posible que ese muerto, Wegener, sea Roschmann. Mi ficha sobre Roschmann no es demasiado completa ${ }^{72}$.

Más allá de descreer de la muerte de Federico Wegner, alias empleado por Roschmann, tal como había desconfiado antes de los restos de Bormann y todavía desconfiaría de aquéllos de Mengele, la antes mencionada alusión de Segev a la excelencia sin igual de Wiesenthal como manipulador de la verdad, así como de la prensa y otros vuelve a asomar su cabeza. De ser textual la transcripción de Serra, y en su apoyo cabe señalar que Segev también recogió la frase del cazador sobre el cadáver de otra persona sustituyendo al que se exhibía como perteneciente a Roschmann, Wiesenthal mostró, en efecto, no tener muy al día el dossier del ex "carnicero de Riga». Y apareció dándole más crédito a Forsyth que a su propio legajo sobre éste, pese a su bien evidenciada dificultad para admitir fallas y estrecha colaboración con el novelista. A la luz de esta última, resulta poco creíble que los descubrimientos de Forsyth no habrían sido compartidos con Wiesenthal, en particular cuando podían ser críticos para la identificación de Roschmann. Los papeles del cazador también dan fe que le tomó hasta dos días, muchísimo menos tiempo que en los casos de Bormann y Mengele, admitir que el muerto no era un suplente provisto por la ilusoria ODESSA. Claro que Bormann cayó antes de acabada la guerra y los esfuerzos de Wiesenthal en relación a Mengele sólo cobraron importancia cuando su fallecimiento lo había colocado fuera del alcance de éste. A diferencia de ellos, Roschmann no resistió, según Segev, la detección del cazador, con lo cual la inducción de Wiesenthal a Forsyth para que se ocupase de él en su novela ODESSA había sido menos infructuosa que su quehacer respecto de los otros dos. Aun cuando Roschmann también eludió a la justicia, el limitado éxito de Wiesenthal fue algo menos acotado si se factorea, por añadidura, la irrefutable contribución de Forsyth a de-

\footnotetext{
72 Alfredo Serra, Nazis en las sombras. Siete historias secretas, Atlántida (en conjunto con la AMIA), Buenos Aires, 2008, pp. 116-118. Este volumen refleja muy bien el conocimiento del tema por los periodistas de línea locales que cubrieron, en su momento, los casos de Klaus Barbie, Walter Kutschmann y Eduard Roschmann.
} 
jar mejor instalado el nombre de la quimérica ODESSA. Tal lo ilustrado por el formador de docentes argentinos Alberto Sarramone. Con acierto, él reconoce al británico como legitimador del nombre ODESSA, reconocimiento que inadvertidamente para Sarramone es también extensible a Wiesenthal (sin haber sido el primero en emplear esa denominación, éste sí fue su más asiduo explotador). Pero Sarramone se aparta de los hechos al endilgarle a Forsyth la paternidad de ese nombre "fruto de la fantasía», o cuando, basado en Goñi, presenta a Perón, «en connivencia con la Iglesia Católica desde el Vaticano, y algunos funcionarios de ciertos Estados europeos», como organizador y sustentador de la ODESSA ${ }^{73}$. Simplificadoras de realidades más complejas, ambas irrealidades están ligadas a elementos de la realidad.

Dado el descreimiento inicial de Wiesenthal y su acomodación de los hechos a ideas preconcebidas, el más detallado volumen sobre Roschmann que preparó el diplomático e historiador alemán Heinz Schneppen es particularmente provechoso. Éste está basado en documentación germana y la mejor historiografía disponible, aquélla que ya procesó el material de archivo europeo oriental ingresado al dominio público en años recientes. Atinadamente, Schneppen concluyó que «el Holocausto es tratado en la ODESSA de manera semificticia y semifáctica, entrelazándose allí lo cierto con lo erróneo, lo trasmitido con lo imaginado (...) En la dificultad o imposibilidad de distinguir lo falso de lo cierto está el peligro de esta clase de sficción factualizada » ${ }^{74}$. Similares juicios críticos sobre la literatura que se mueve en esa zona de ambigüedad fueron vertidos por otros estudiosos reconocidos, entre ellos Raul Hilberg, sin que quepa ignorar cierta semejanza entre lo dicho por Schneppen sobre Forsyth y la conclusión de Segev luego sobre hechos y ficciones en la vida y trabajo de Wiesenthal. El riguroso capítulo que Schneppen le dedicó a los testigos y sus testimonios, entre ellos a las memorias de sobrevivientes de ese ghetto, muestra la fructífera confluencia de la metodología de la indagación judicial con la tarea historiográfica, ilustrando además que el Roschmann de Forsyth es, en su núcleo auténtico, un personaje construido. Allí se mezclan los rasgos y las atrocidades de varios perpetradores, siendo el perfil más aberrante el del verdadero "carnicero de Riga», Rudolf Lange, coro-

\footnotetext{
73 Alberto Sarramone, Alemanes en la Argentina. Inmigración, refugiados judíos y nazis con Perón, Buenos Aires, Ediciones B, 2011, pp. 253-254.

74 Heinz Schneppen, Ghettokommandant in Riga Eduard Roschmann. Fakten und Fiktionen, Berlín, Metropol, 2009, pp. 211-212.
} 
nel de las SS y doctor en derecho. Pero, a diferencia de Roschmann, Lange fue descartado para la obra de Forsyth por no haber sobrevivido al Tercer Reich ${ }^{75}$.

Las ficciones de Wiesenthal sobre Estrasburgo y la ODESSA se ven realzadas por la presencia de Walter Rauff, inventor de la cámara de gas rodante, entre los líderes de esa organización, contándose Otto Skorzeny en un rol conductor asimismo, según ciertas versiones ${ }^{76}$. Curiosamente, empero, Rauff colaboró desde Siria con la inteligencia israelí en la temprana posguerra, y Skorzeny, considerado al igual que Rauff como criminal de guerra por Wiesenthal, hizo lo mismo años después en Egipto. Si bien los papeles consultados por Segev sugieren que el cazador desconocía ese antecedente de Rauff, estaba al corriente de aquél de Skorzeny. Sin embargo, la devaluación de la caza de criminales de guerra implícita en la emulación israelí a otros servicios de inteligencia, que también reclutaron a ex criminales nazis
- piénsese, por caso, en la labor de Barbie para el CIC estadounidense-, no llevó a Wiesenthal a expresarse al respecto, siendo interesante contrastar ese silencio con su diplomacia del megáfono, empleada para sermonear a otros países. A imagen y semejanza de Wiesenthal, difícilmente asombre que Camarasa no haya aludido a la colaboración de Skorzeny con la inteligencia hebrea, tal como lo hicieron varios historiadores, siendo Segev de los primeros en difundirlo en una obra previa.

La inexistencia de la ODESSA provocó distintas reacciones entre los periodistas argentinos antes mencionados. Nadie como De Nápoli, sin embargo, en materia de originalidad al respecto. Éste optó por referirse a una Spinngewebe (Telaraña), que recuerda a La Araña como «la organización que estructuraron los nazis para facilitar la fuga ${ }^{77}$. Siendo tales arácnidos y su quehacer menos conocidos en Argentina que una ODESSA desacreditada -si bien el nombre sigue empleándose para refutar su

\footnotetext{
75 La valiosa yapa de este libro está plasmada en el estudio de la llegada de Roschmann aquí. A contramano de Wiesenthal y, por ende, de Forsyth, Schneppen muestra la evidencia de la participación de un elenco de actores menos sensacionalista que la imaginaria ODESSA en su arribo aquí: contrabandistas y simpatizantes nazis, o fascistas austríacos e italianos; la Cruz Roja en tandem con el organismo vaticano para refugiados y el obispo austríaco Alois Hudal, así como representantes de las autoridades inmigratorias argentinas, sin por ello ignorar a un tío de su mujer aquí, al que el prófugo acudió para la compra de su pasaje a Buenos Aires.

${ }^{76}$ Desde su radicación en Chile, Rauff sobrevivió varios pedidos de extradición, ninguno presentado por Israel. Puede pensarse que ese rol de Rauff en Siria, y aquél en el equipo germano que negoció con Estados Unidos la rendición alemana en Italia, tuvieron su parte en su inmunidad a la extradición. Klich, «El ingreso», p. 419.

77 De Nápoli, La fórmula, p. 12.
} 
inexistencia y para subrayar las deficiencias de quienes insisten en negar su irrealidad-, ésta fue la creativa opción elegida por De Nápoli para seguir aludiendo a la mítica ODESSA sin tener que nombrarla. Y en lo atingente al botín traído al país por los auspiciados de la ODESSA, Camarasa remite a un artículo en la revista Somos con tal abundancia de pifias como para tener que tomar ese inventario cum grano salis ${ }^{78}$. Más importante que tales ardides es tener presente que la quimera de la ODESSA de ninguna manera significa ignorar las redes que ayudaron a distintos nazis en huida a mudarse a este continente, Oriente Medio $\mathrm{u}$ otros destinos.

Del lado argentino, ya se mencionaron los documentos de viaje provistos por el gobierno de Perón. Adicionalmente, las investigaciones de la antes aludida CEANA determinaron que luego de un encuentro con Perón de 1947 distintos europeos recién desembarcados crearon, con venia oficial, la Sociedad Argentina de Recepción de Europeos. Por menos de un año ésta asistió a conseguir los requeridos permisos de libre desembarco argentinos a distintos necesitados, especialmente a aquéllos que habían actuado en los regímenes del Eje, criminales incluidos ${ }^{79}$. Mucho antes, la policía de Flensburgo repartió hacia el final de la guerra papeles falsos a centenas de funcionarios. Buscando darles refugio al interior de Alemania, algunos personajes organizaron por su cuenta dos centros clandestinos - la Hermandad y el Círculo de los Gauleiter-, además de células más pequeñas basadas en relaciones personales. Figuras influyentes de la Iglesia jugaron, independientemente, un rol facilitador importante en la huida de Europa de quienes así lo requerían. A su turno, los intereses compartidos por el general alemán Reinhard Gehlen, el ejército estadounidense y la antecesora de la CIA produjo a partir de 1946 un servicio secreto que dio trabajo a numerosos ex agentes nazis. Algo parecido ocurrió con el grupo de Otto von Bolschwing y las operaciones Apple Pie y Bloodstone, conducidas por los servicios anglonorteamericanos. Al otro lado de la cortina de hierro, no faltaron ex nazis reubicados en el aparato estatal de la RDA. Parte de estos agrupamientos tuvo laxa supervisión de un gobierno, siendo los demás autónomos y hasta hostiles entre sí. Un mando y planificación centralizados, como lo postulan quienes hablan de una ODESSA de alcance mundial, no hubo ni es ajeno al género de la ficción, restando escribirse una historia integral de toda esta semisecreta zona de conexión

\footnotetext{
78 Camarasa, Puerto seguro, p. 115.

79 Diana Quattrocchi-Woisson, «Relaciones con la Argentina de funcionarios de Vichy y de los colaboradores franceses y belgas, 1940-1960», en Klich, Inmigrantes, pp. 217-222.
} 
entre la Europa del Eje y el mundo de la Guerra Fría.

Expuesta la deformación de Wiesenthal del documento sobre Estrasburgo y la ODESSA, tienden a quedar asimismo más expuestas otras alegaciones suyas, algunas ligadas a la Argentina y mencionadas en sus memorias, aunque no tratadas por Segev. Sin ser las únicas, tal, por ejemplo, es el caso de los 60.000 criminales de guerra del nazismo acogidos por Perón y la supuesta recompensa de 100 millones de dólares, cuando no el doble, que ello le habría redituado, datos cronológicamente precedidos por el cálculo de 60.000 afiliados en Argentina del partido nazi (NSDAP), cifras todas ellas irrepetibles por no encontrarse seriamente evidenciadas $^{80}$. Por ańadidura, no es mera casualidad que casi todos los periodistas que mencionaron el arribo de criminales de guerra del nazismo aquí aludieron, explícita o implícitamente, a la falseada versión de Wiesenthal sobre Estrasburgo. Y sirviéndose de ella, trataron de llenar los espacios dejados vacantes, sea sobre las facilidades a disposición de los que afluyeron, o a propósito del expolio que trajeron, incluso a bordo de submarinos más tarde hundidos. Pero cuyos restos, valga la repetición, están muy lejos, por supuesto, de haber sido hallados.

Complementando la versión de Wiesenthal sobre Estrasburgo y la ODESSA, Camarasa creyó haber logrado echarle mano a un documento de la Policía Federal, de copia facsimilar reproducida en su primer libro sobre Argentina y los nazis. Datando de 1967, este registro sirvió de punto de arranque para un par de notas emitidas por el semanario Última Clave, antes de que Camarasa lo aborda-

\footnotetext{
${ }^{80}$ Aportada por Wiesenthal, la cifra de 60.000 criminales de guerra del nazismo acogidos aquí es muy superior al saldo migratorio de alemanes y austríacos, cualquiera su filiación política o confesional, que se radicaron en el país durante 1945-1955, más el total de los alemanes étnicos con filiaciones semejantes, detentadores de otras nacionalidades, y los nazis venidos con identidades asumidas. Coincidentemente, Wiesenthal había mencionado antes que la rama argentina del partido nacionalsocialista alemán (NSDAP) tuvo el mismo número de afiliados, cantidad que tomó prestada de Raúl Damonte Taborda, ex presidente de la CIAAA, y que seguía repitiendo dos décadas después de que el Senado estadounidense tuvo documentado en 1946 que fueron menos de 2.500. Joseph Wechsberg (ed.), The Murderers among Us: The Simon Wiesenthal Memoirs, Nueva York, 1967, p. 338; Ignacio Klich, «Perón, Braden y el antisemitismo: opinión pública e imagen internacional», Ciclos, vol. 2, №2, 1992, pp. 19-20. Habiendo argumentado en Los nazis en la Argentina (Legasa, Buenos Aires, 1992) que Perón fue retribuido con una casa en la capital egipcia, y más tarde caído en la cuenta que estaban en lo cierto quienes sostenían que una recompensa tal no habría sido una muestra de agradecimiento, Camarasa abandonó tal residencia cairota a favor de una tampoco documentada millonada, mencionada en su Odessa al Sur. La Argentina como refugio de nazis y criminales de guerra (Buenos Aires, Planeta, 1995).
} 
ra. Allí se decía que Perón, en calidad de jefe de la logia militar con la que llegó al poder en junio de 1943, había accedido a un pedido del embajador alemán: alrededor de 20.000 documentos de identidad argentinos para quienes estarían expuestos a persecuciones en la posguerra. Tales papeles en blanco le fueron remitidos a Himmler en Estrasburgo en agosto de 1944 a través del attaché militar germano Von Leers. Claro que tan denodado esfuerzo por ligar los documentos de viaje argentinos con la conferencia de Estrasburgo es difícil de conciliar con la cronología de los personajes e instituciones nombradas. Por caso, el embajador del Tercer Reich en Buenos Aires retornó a Berlín para siempre a inicios de 1942, y el GOU no fue creado antes de fines de ese año. Es decir que Perón no habría podido satisfacer un pedido tal, en caso de habérselo hecho ese representante germano. Y Von Leers, que no era diplomático ni se encontraba en Argentina en la primera mitad de los años cuarenta, no llegó al país como Hans Euler antes de 1946, ni post-1950, siendo parte de la afluencia nazi, no enviado oficial ${ }^{81}$. Pese a un dechado de imprecisiones que excede a las arriba expuestas, la reproducción completa de este documento policial por parte de Camarasa se concretó sin alertar al lector menos bien informado sobre tales minusvalías decisivas ${ }^{82}$.

En suma, bien leído, Segev ha producido una biografía de Wiesenthal que, pese a lo señalado sobre Estrasburgo y la ODESSA, contribuye a su desmitificación, no así a la de otros cazadores, ni por supuesto a su justa causa. Remediable en alguna futura edición, si su autor así lo deseara, la consulta del documento sobre la reunión en la capital alsaciana engalanaría a este de por sí valioso volumen. Lo mismo puede decirse sobre un relevamiento de las deformaciones wiesenthalianas acerca de la Argentina, importante secuela rioplatense de las distorsiones sobre las que este cazador construyó su celebridad. Con prescindencia de lo antedicho, está claro que este volumen de Segev, junto al de Schneppen, es desde lejos, parte de la literatura altamente recomendable sobre Argentina, o de relevancia para ésta. En

\footnotetext{
${ }^{81}$ De haber arribado antes de 1949, ello agregaría dudas al hallazgo de un periodista estadounidense, descubridor ese año de La Araña, con Von Leers a su cabeza. Ignacio Klich, «Documentos, desinformación y la llegada de nazis al Río de la Plata», en: Hellen B. Soriano (comp.), Encuentro y alteridad. Vida y cultura judía en América Latina, México, UNAM/Universidad Hebrea de Jerusalén/ Asociación Mexicana Amigos de la Universidad de Tel Aviv/Fondo de Cultura Económica, 1999, p. 332; Breitman \& Goda, p. 60.

82 Para un análisis de ese documento, ver Ignacio Klich, «The Nazis in Argentina: Deconstructing Some Myths», Patterns of Prejudice, vol. 29, № 4, 1995; ver también Klich, «Documentos».
} 
cambio, los mitos alentados en obras de los periodistas locales reseñados tienden a ilustrar, entre otras cosas, una elementalidad algo rasa de su conocimiento sobre el tema. No en vano Schneppen observó que es «seguro que la ignorancia juega un papel, ya que a los productores de mitos les falta tanto el conocimiento de la materia, como el del oficio del historiador ${ }^{83}$. Pero esas obras periodísticas también evidencian el condicionamiento de sus autores a nociones previas que los atraviesan, realidad ésta que ha actuado como obstáculo mayor para el reemplazo de lo fabulado por el material serio de archivo. Con ese trasfondo, puede concluirse que el ejemplo de Wiesenthal, sin ser el único, fue influyente para ciertos periodistas locales -no sólo De Nápoli, Camarasa y Basti-, exacerbando su propensión a fantasear.

Comparado con los antes mencionados, parece un pobre halago, independientemente de su precisión y ajuste a la realidad, referirse a la edición revisada del tomo de Goñi sobre los criminales venidos al país, y sus vías de ingreso aquí, como descollante en el terreno del periodismo investigativo local. Cierto es que este libro se acerca más a lo acostumbrado en el ámbito anglosajón, donde se publicó su versión inicial en $2002^{84}$, es decir mayor relevamiento de materiales de archivo e historiografía. Pero tales atributos no justifican su estilo expositivo, que puede alentar al lector no especializado a creer que se trata de una obra definitiva, en principio algo de por sí generalmente difícil, pero que además no es el caso por una diversidad de razones adicionales, abordadas más abajo.

Cuantitativamente significativa, su bibliografía adolece, empero, de notables ausencias: no incluye a más de una docena de trabajos importantes, que permiten ubicar el tema de la afluencia nazi en su dimensión multinacional ${ }^{85}$, y dar una imagen adecuada de la magnitud y estructura de

${ }^{83}$ Heinz Schneppen, Odessa und das Vierte Reich. Mythen der Zeitgeschichte, Metropol, Berlín, 2007, p. 214.

${ }^{84}$ Para recensiones de The Real Odessa: How Perón Brought the Nazi War Criminals to Argentina, de Uki Goñi, Granta, Londres, 2002, ver, por ejemplo, Ignacio Klich, en: Antisemitism Worldwide 2002/3, Universidad de Tel Aviv, 2004, pp. 81-84; Cristian Buchrucker, en: Estudios Sociales, año XIV, n 27, 2004, pp. 200-204.

${ }^{85}$ Los ausentes incluyen, por caso, a Clive Ponting, Armageddon: The Reality Behind the Distortions, Myths, Lies, Illusions of World War II, Random House, Nueva York, 1995; Christiaan F. Ruter \& Dick W. de Mildt (eds.), Justiz und NS-Verbrechen: Sammlung deutscher Strafurteile wegen nationalsozialistischer Totungsverbrechen, Amsterdam University Press, Amsterdam, 1968; Matthias Schoenwald, Deutschland und Argentinien nach dem Zweiten Weltkrieg. Politische und wirtschaftliche Beziehungen und deutsche Auswanderung 1945-1955, Schoeningh, Paderborn, 1998; Reinhard R. Doerries (ed.), Hitler's Last Chief of Foreign Intelligence: Allied Interrogations of Walter Schellenberg, Cass, Londres, 
sus apoyos argentinos. En cambio, aporta una serie de afirmaciones que no terminan de ser desarrolladas, ni fundamentadas. Esto es tanto más destacable por cuanto el relato de Goñi muestra que el arribo de nazis, contrariamente a lo que éste procura demostrar, fue una empresa multinacional, más vasta que la mencionada por él.

El tratamiento de Goñi de los criminales nazis arribados, sus apoyos locales y otros, también aleja a esta edición revisada de una obra definitiva sobre el tema. Está claro que las fabulosas cifras difundidas por Wiesenthal y otros han caído en desuso, consignadas a la pouvelle de l'histoire, subsistiendo discrepancias menores en materia de conteo. Ya se mencionó que los estudios de la CEANA señalaron como criminales de guerra al menos a $180 \mathrm{eu}$ ropeos de distintas nacionalidades, $27 \mathrm{de}$ ellos alemanes y austríacos, en tanto que Goñi-presentador de ese mismo total en una obra previa de 1998, sin mencionar a la CEANA-, más tarde llegó a creer que ellos fueron 228, de entre los cuales 33 serían alemanes y austríacos. Pero Goñi no se interesa en la relación entre tales cantidades y la totalidad de las personas impli- cadas de manera directa o indirecta en el aparato represivo y genocida del nazismo, relación clave para evaluar la dimensión argentina del fenómeno.

El universo de los implicados en tal aparato excedió las 250.000 almas. Desde 1945, y hasta la década de 1960, los angloamericanos, franceses, alemanes y los gobiernos comunistas procesaron como criminales a una cantidad en exceso de 38.000 alemanes, además de los 24 de Nuremberg. Otros miles fueron ejecutados en 19451946 merced a sumarísimos juicios de países como Yugoslavia, o se suicidaron en los últimos meses de la guerra. Frente a esos miles, los llegados aquí, importantes cualquiera su número, fueron más bien pocos, conclusión voceada por el académico anglogermano Ralf Dahrendorf en su evaluación de los trabajos de la CEANA como miembro de su Panel Internacional.

$\mathrm{Y}$ ante la pregunta de si Argentina fue el país que albergó al mayor número de tales criminales, cabe volver sobre algo ya señalado por el historiador Herbert. Si bien no hay estadísticas para cada país, al menos se cuenta con buena información sobre Alemania y Austria. De ésta surge

2003; Richard Breitman, Norman J.W. Goda, Timothy Naftali \& Robert Wolfe, U.S. Intelligence and the Nazis, Cambridge University Press, Cambridge, 2005; Uwe Luebken, Bedroliche Nahe: Die USA und die nationalsozialistische Herausforderung in Lateinamerika, 1937-1945, Franz Steiner, Stuttgart, 2004; Ernst Klee, Das Personenlexikon zum Dritten Reich. Wer war was vor und nach 1945, S. Fischer, Francfort del Meno, 2007; Holger Meding \& Georg Ismar (eds.), Argentinien und das Dritte Reich. Mediale und reale Praesenz, Ideologietransfer, Folgenwirkungen, Wissenschaftlicher Verlag, Berlín, 2008. 
que fue allí -pese a la ocupación aliadadonde se refugio la mayoría de los que tenían algo que temerle a la justicia. Baste con revisar el diccionario biográfico de Ernst Klee para encontrar, por caso, 131 alemanes y austríacos de esa clase entre los comprendidos entre las letras A y la $\mathrm{H}$. Sólo 28 de estos fueron procesados, y ello recién en las décadas de 1960-1970, tras larga permanencia suya en la clandestinidad. Muchos del resto incluso no tuvieron mayores inconvenientes para ubicarse en buenos trabajos civiles. Por tanto, la obra de Klee no sólo ayuda a evidenciar la conclusión de Herbert, sino también confirma aquélla de hace medio siglo, entonces impresionista, de otro autor germano, Tete Hare Tetens, sobre el liderazgo alemán en materia de refugio para criminales. Nada de ello, por supuesto, asoma en la obra de Goñi.

Goñi también acompaña a los periodistas e historiadores que mostraron la facilidad con que el interés en los así llamados «alemanes útiles» llevó a ahorrar indagaciones sobre las credenciales profesionales de técnicos, militares o meros trabajadores anticomunistas invocadas por ciertos represores y genocidas del Tercer Reich y aliados. Pero deja la impresión que esa receptividad habría sido una peculiari- dad local, cosa que no puede sostenerse con fundamento: más bien fue la norma en esa época. Los esfuerzos tendientes a identificar, controlar y procesar languidecieron después de 1946 y un documento argentino hallado antes de la CEANA demostró que las propias autoridades estadounidenses manifestaron en febrero de 1947 que cada país del hemisferio americano debía tener «completa libertad de acción" para ocuparse de todos esos euro$\operatorname{peos}^{86}$. Por su parte, la justicia alemana y austríaca no se mostraron muy laboriosas para tramitar extradiciones: para los 27 candidatos identificados en la Argentina no hubo sino nueve averiguaciones a lo largo de cinco décadas, de las cuales sólo dos fueron en 1949-1955.

Por último, resulta asombroso que dos yerros importantes de Goñi, corregidos en la versión alemana de este volumen no hayan sido enmendados en esta reedición. Es posible ligar esas correcciones al deseo de sus editores germanos de rescatar a Goñi de un par de errores significativos sobre dos otrora diplomáticos del Tercer Reich, Karl Klingenfuss y Franz Rademacher, de modo parecido a como la editora italiana de Camarasa lo hizo con su descreimiento de la muerte de Bormann ${ }^{87}$. Corolario, el hispano ha-

${ }^{86}$ Ver, por ejemplo, Klich, «El ingreso», pp. 415-416.

${ }^{87}$ Schneppen, «De todas las Odessas», p. 238, n. 60, pp. 239-240, n. 73; Klich \& Buchrucker, p. 273. 
blante no ha tenido la suerte del público germano: en alemán, Goñi se abstiene de presentar a Klingenfuss como responsable del hundimiento de una nave con más de 750 judíos deseosos de llegar a Palestina -677 en la estimación errada de Goñi-, rol que Schneppen demostró que éste jamás tuvo, ni pudo haber tenido. En alemán, Goñi también evita hacernos creer que Rademacher se refugió en Argentina, país al que no vino. Contrastando con ese acierto de los editores germanos, nadie extirpó del manuscrito otros errores, tanto o más gruesos que éstos. Así, por caso, sigue pudiendo leerse en esta reedición que el manifiesto del GOU de mayo de 1943, claro en su contenido nazi, habría sido escrito por Perón, si bien esa proclama muy citada era un documento fraguado: ni forma parte del volumen documental sobre esa logia militar del estadounidense Robert Potash, y su falsía fue señalada por varios historiadores, ni Goñi ofrece evidencia alguna para reconsiderar tal falsedad. Sin aportar pruebas, Perón también habría sido para Goñi el autor de textos judeófobos del GOU, que el historiador italiano Loris Zanatta logró establecer hace tiempo provenían del padre Wilkinson. Y en cuanto al publicista nacionalista Juan Carlos Goyeneche, dice que desde antes de 1942 éste viajaba en «misiones secretas» a Alemania, antesala a una «alianza» jamás concretada de la Argentina del GOU con esa potencia ${ }^{88}$.

Ciertamente, Goñi no consultó la documentación diplomática germana, mostrándose además reluctante a abandonar ciertos artículos de fe, como el quimérico pronunciamiento pronazi del GOU, los escritos judeófobos de Perón et al. Ninguno de ellos posee base documental, salvo que se le asigne tal calidad a la literatura de combate de los decenios de 1940 y 1950 . Más sutil que sus ya mencionados pares, Goñi comparte con ellos, empero, un sesgo antiperonista, bien reflejado en sus escritos. Sólo que a diferencia de los tres periodistas antes aludidos, refractarios a una consulta rigurosa de los registros disponibles -actitud afín a aquella de Wiesenthal vis-à-vis la documentación sobre Estrasburgo-, Goñi ha revisado más material de archivo. De ahí la creencia implícita que sus cuantiosas notas al pie tornan menos perceptible la carencia de soporte documental para ciertas ficciones. Más generalmente, Basti, Camarasa, De Nápoli y Goñi parecen intuir la inexistencia de material serio en repositorios re-

\footnotetext{
88 Uki Goñi, La auténtica Odessa. Fuga nazi a la Argentina, Paidós, $2^{\circ}$ edición actualizada, Buenos Aires, 2008, pp. 16, 34, 55 y 72. A propósito de Goyeneche, ver Cristian Buchrucker, Nacionalismo y peronismo. La Argentina en la crisis ideológica mundial (1927-1955), Sudamericana, Buenos Aires, 1987, pp. 227-230.
} 
huidos o incompletamente relevados para sustanciar ciertas nociones míticas. Sin proponérselo, un texto del periodista argentino Pablo Sirvén pone de manifiesto cuán marcada, y por ende condicionante de los respectivos textos de este cuarteto, es la intensidad de su sesgo político. La simpatía inexistente de Sirvén para con los «buenos aprendices de Mussolini y Hitler» en el GOU no le impide anotar que éstos, «por supuesto, eran mucho más inofensivos», y que la visión del gobierno militar como «un retoño del fascismo», si bien lógica en el período bélico, era funcional a una creciente "psicosis» animada por los aliados para que Argentina abandonara la neutralidad. Asimismo, Sirvén presenta a "la ayuda nazi que habrían recibido las autoridades militares antes de la caída del Tercer Reich», y a alusiones a
Perón como el «coronel nazi» durante la campaña electoral y presidencia de éste, como parte de un enfrentamiento en el que unos y otros se endilgaron «los más absurdos cargos» ${ }^{89}$.

Habiendo acertado Goloboff al señalar que «lo mítico del mito es que no puede cercárselo, que no se acaba, que siempre continúa interrogándonos, más allá de toda razón, de toda lógica, de toda experiencia material», es crucial acentuar la prescindencia del razonamiento y de la documentación, más allá de la ignorancia ya señalada por Schneppen, como ingredientes esenciales para que autores como Basti, Camarasa, De Nápoli y Goñi sigan alimentando mitos sobre Argentina y los nazis ${ }^{90}$. Pero no es con esos insumos que se ha de avanzar con la afirmación de una cultura política democrática local.

89 Pablo Sirvén, Perón y los medios de comunicación. La conflictiva relación de los gobiernos justicialistas con la prensa 1943-2011, Buenos Aires, Sudamericana, 2011, pp. 70, 93 y 98.

90 Página/12, 28/04/2011. 